\title{
CAPITAL UTILIZATION AND RETURNS TO SCALE
}

\author{
Craig Burnside \\ Martin Eichenbaum \\ Sergio Rebelo
}

Working Paper No. 5125

\section{NATIONAL BUREAU OF ECONOMIC RESEARCH 1050 Massachusetts Avenue Cambridge, MA 02138 May 1995}

The authors owe a deep debt of gratitude to Joe Beaulieu. This paper would not have been possible without his help. In addition, we would like to thank Ben Bernanke, Mark Bils, Lawrence Christiano, John Fernald, Joe Mattey, Julio Rotemberg, Matt Shapiro, and Steve Strongin for useful conversations. This paper is part of NBER's research program in Economic Fluctuations. Any opinions expressed are those of the authors and not those of the National Bureau of Economic Research.

(C) 1995 by Craig Burnside, Martin Eichenbaum, Sergio Rebelo. All rights reserved. Short sections of text, not to exceed two paragraphs, may be quoted without explicit permission provided that full credit, including $\odot$ notice, is given to the source. 


\title{
CAPITAL UTILIZATION AND \\ RETURNS TO SCALE
}

\begin{abstract}
This paper studies the implications of procyclical capital utilization rates for inference regarding cyclical movements in labor productivity and the degree of returns to scale. We organize our investigation around five questions that we study using a measure of capital services based on electricity consumption: (1) Is the phenomenon of near or actual short run increasing returns to labor (SRIRL) an artifact of the failure to accurately measure capital utilization rates? (2) Can we find a significant role for capital services in aggregate and industry level production technologies? (3) Is there evidence against the hypothesis of constant returns to scale? (4) Can we reject the notion that the residuals in our estimated production functions represent technology shocks? (5) How does correcting for cyclical variations in capital services affect the statistical properties of estimated aggregate technology shocks? The answer to the first two questions is: yes. The answer to the third and fourth questions is: no. The answer to the fifth question is: a lot.
\end{abstract}

Craig Burnside Department of Economics University of Pittsburgh Pittsburgh, PA 15260
Martin Eichenbaum Department of Economics Northwestern University Evanston, IL 60208 and NBER
Sergio Rebelo

Department of Economics University of Rochester Rochester, NY 14627 and NBER 


\section{Introduction}

This paper studies the implications of procyclical capital utilization rates for inference regarding cyclical movements in labor productivity and the degree of returns to scale. To study cyclical movements in capital utilization we use two measures of capital services: industrial electrical use and data on the workweek of capital. The investigation addresses five questions using different assumptions about the production technology:

1. Is the phenomenon of near or actual short run increasing returns to labor (SRIRL) an artifact of the failure to accurately measure capital utilization rates?

2. Can we find a significant role for capital services in aggregate and industry level production technologies?

3. Is there evidence against the hypothesis of constant returns to scale?

4. Can we reject the notion that the residuals in our estimated production functions represent technology shocks?

5. How does correcting for cyclical variations in capital services affect the statistical properties of estimated aggregate technology shocks?

Briefly, the answers are: (1) yes, (2) yes, (3) no, (4) no, and (5) a lot.

Our investigation utilizes aggregate data and two new data sets: a panel on 2-digit SIC industries and a panel on 3-digit SIC industries. We argue that the data are well described by a constant returns to scale production function. The estimated coefficients on labor and capital services are similar to the shares of labor and capital in national income, .64 and .36, respectively. The estimated residuals from our estimated production technology have two important properties. First, in most cases, they pass a variant of Hall's (1988) invariance test; they are consistent with a set of orthogonality conditions that candidate measures of technology shocks ought to satisfy. In contrast, the traditionally calculated Solow residual does not pass the Hall test. Second, they are much less volatile and less correlated with aggregate output than the empirical measure of technology shocks used in the Real Business Cycle (RBC) literature.

The observation that average labor productivity is procyclical, which goes back at least as far as Fabricant (1942), is closely related to a well known puzzle: capital appears to play no role in explaining cyclical movements in output. This puzzle has been stressed by Solow 
(1964), Lucas (1970), Bernanke and Parkinson (1991), among others. Exploring different data sets over different sample periods and using different estimation strategies, they arrive at the same conclusion: capital enters estimated production functions with either the wrong sign or not at all.

The typical reaction is to this finding is to ignore movements in capital when studying cyclical productivity fluctuations. While disheartening, Perry (1973)'s rationale for doing this seems compelling:

'If capital is ignored, it is for a simple pragmatic reason: one cannot find an important or statistically significant role for capital in a freely estimated aggregate production function or any equivalent relation that one might use in estimating potential output.'

An alternative response is to obtain better measures of capital services. This is the strategy we pursue. And with better measures, we find that there is an important and statistically significant role for capital services. Moreover, estimated returns to scale are roughly constant.

A different reaction to the apparent unimportance of capital in estimates of production functions is to stop estimating them. In the macro literature, authors like Hall (1988) have studied returns to scale by relating the growth rate of output to a cost weighted sum of the growth rates of inputs. We implement the Hall type strategy using our measures of capital services to assess the robustness of our findings. The key result is that, with this approach too, we cannot reject the hypothesis of constant returns to scale.

Using our measures of capital utilization, we argue that neglecting cyclical variations in capital services affects inference about why average labor productivity is procyclical. This is important because the procyclical nature of average labor productivity has played a central role in recent debates about the causes of aggregate economic fluctuations. RBC theorists, such as Kydland and Prescott (1982) and Long and Plosser (1983) emphasize the importance of exogenous shocks to productivity as the main impulse to postwar US business cycles. With shocks to the aggregate production technology, RBC models can account for the observed procyclical nature of labor productivity. Other researchers, sometimes organized under the 
'New Keynesian' banner, have sought to revive much of the common wisdom associated with the IS-LM paradigm using models grounded on microeconomic foundations. ${ }^{1}$ These researchers emphasize the importance of demand shocks as impulses to economic fluctuations. In conjunction with increasing returns to scale, demand shocks too can generate procyclical movements in productivity. ${ }^{2}$

Increasing returns to scale are also an essential ingredient in a recent strand of literature that emphasizes the importance of multiple equilibria for understanding business cycles. ${ }^{3}$ In standard RBC models the competitive equilibrium can generally be characterized as the solution to a planning problem, which, being a concave program, has a unique solution. With increasing returns the resource constraints facing the economy no longer define a convex set, so there can be more than one equilibrium path. Under these circumstances, recessions can be the result of pessimistic, self fulfilling beliefs of agents in the economy. With increasing returns to scale, low output and employment levels will be associated with low levels of labor productivity.

An alternative explanation of procyclical productivity, and the one which is most relevant to this paper, focuses on cyclical movements of capital utilization and labor hoarding. This explanation has recently been explored by, among others, Greenwood, Hercowitz and Huffman (1988), Kydland and Prescott (1988), Burnside, Eichenbaum and Rebelo (1993), Finn (1991), Basu and Kimball (1994), Bils and Cho (1994) and Burnside and Eichenbaum (1994).

Given the importance of disentangling the sources of procyclical productivity, analyzing the properties of the Solow residual and estimating the degree of returns to scale have become priority items in the macroeconomics research agenda. Authors like Basu and Kimball (1994) use industry level annual data to assess the contribution of unobserved input variation to cyclical movements in total factor productivity. Shapiro (1993a) uses annual data to study the importance of movements in the workweek of capital. A different body of research, originally associated with Hall $(1988,1990)$, focuses on the returns to scale and externalities.

\footnotetext{
${ }^{1}$ See Mankiw and Romer (1991) as well as the references therein.

${ }^{2}$ Rotemberg and Summers (1990) combine labor hoarding behavior along with nominal price rigidities as a way of rationalizing the cyclical behavior of average labor productivity. Perhaps this defines them as 'Old' Keynesians.

${ }^{3}$ See for example Farmer and Guo (1995), Rotemberg and Woodford (1995) and the references therein.
} 
Hall $(1988,1990)$ claimed to find evidence of large markups and increasing returns to scale. Using similar methods, Caballero and Lyons (1992) and Bartelsman, Caballero and Lyons (1994) argue that there are large spillover externalities at the industry level.

Bartelsman (1993) suggests that Hall's evidence of large increasing returns to scale can be explained entirely by the presence of small sample bias in Hall's econometric procedures. A different criticism has been levied by Basu and Fernald (1994a,b) who argue that with imperfect competition, the use of value added data leads to spurious findings of large increasing returns to scale and external effects. Indeed, they show that when gross output data on 2 digit SIC industry level data is used, evidence of increasing returns and externalities disappears. ${ }^{4}$ In addition, at this level of aggregation, findings of external spillover effects are associated with an exceedingly improbable implication. Estimated total returns to scale is roughly constant. So spillover effects emerge only at the cost of concluding that there are very large internal decreasing returns to scale (see Basu and Fernald (1994a) and Burnside (1994)). One exception to this characterization is the 4 digit SIC industry level study by Bartlesman, Caballero and Lyons (1994).

All of the previous studies use variants of Hall's (1988) methodology in conjunction with annual data. Rather than rely solely on annual data, we consider different specifications of technology that allow us to attack the problem with quarterly aggregate and industry level panel data. As it turns out there are interesting tradeoffs involved in using different specifications of technology. These involve the generality of the specification being considered, the assumptions about market structure and data requirements that are needed to estimate the parameters in question. But overall returns to scale is a dimension across which all of the specifications can be compared. And as it turns out, inference is very robust on this dimension.

In all cases we estimate the parameters of technology using a three stage least squares procedure that exploits the fundamental identifying assumption proposed by Hall (1988):

\footnotetext{
${ }^{4}$ The fact that value added and gross output data yield different estimates of the degree to scale can be explained even in the presence of perfect competition. In order for value added output to correctly measure the marginal productivity of primary inputs, one of the following three restrictions has to hold: (1) materials and energy are used in fixed proportions with gross output (Leontief aggregation), (2) the relative price of materials and energy in terms of gross output is constant (Hicks aggregation), and (3) the gross output function has the form $Y=F[(K, L), M, E]$ (weak separability), where $K, L, M$, and $E$ denote capital, labor, materials and energy, respectively. See Bruno (1978).
} 
shocks to technology ought to be orthogonal to variables that are 'known neither to be causes of productivity shifts nor to be caused by productivity shifts'. In our view, shocks to monetary policy, say as measured by Christiano, Eichenbaum and Evans (1994), as well as variables like the relative price of oil qualify to be included in this class.

The remainder of this paper is organized as follows. Our model is presented in Section 2. Econometric procedures and data sources are detailed in Section 3. Empirical results are presented in section 4. Some important limitations of our analysis are discussed in Section 5. The key problem, as in the related literature, (see for example Hall $(1988,1990)$ and Basu (1993) is the potential impact of unobserved overhead capital and labor on the interpretation of our estimated parameters. Concluding comments are contained in Section 6 .

\section{Model Specification}

We begin by providing an overview of the three specifications of technology used in our empirical work. In addition we summarize the tradeoffs with each specification. These pertain to the generality of the specification, assumptions about market structure and the data needed to implement the model empirically.

Let $Y_{t}$ denote time $t$ gross output. In our first specification we assume that

$$
Y_{t}=\min \left(M_{t}, V_{t}\right)
$$

where $M_{t}$ denotes time $t$ materials and $V_{t}$ denotes a function that involves hours worked $\left(L_{t}\right)$, the stock of capital $\left(K_{t}\right)$ and electricity use $\left(E_{t}\right)$. Capital services and $E_{t}$ are related via a Leontief technology. Our second specification relaxes this assumption and allows for substitution between capital services and $E_{t}$. The third specification abandons the assumption that $M_{t}$ and $V_{t}$ are related via a fixed coefficients technology. Here we assume that $Y_{t}$ is a differentiable function of capital services $\left(S_{t}\right)$, energy $\left(\mathbf{E}_{t}\right), L_{t}$ and $M_{t}$ :

$$
Y_{t}=F\left(S_{t}, L_{t}, \mathbf{E}_{t}, M_{t}\right)
$$

The following Table summarizes the tradeoffs involved in using the different specifications. 


\begin{tabular}{||l|lll||}
\hline \hline & Specification 1 & Specification 2 & Specification 3 \\
\cline { 2 - 4 } Data Frequency & Quarterly, Annual & Quarterly, Annual & Annual \\
Industry Level & 2,3 digit SIC & 2 digit SIC & 2 digit SIC \\
Goods Market & No Assumptions & No Assumptions & No Assumptions \\
Factor Markets & No Assumptions & Hours, Electricity: & All factors: \\
& & Perfect Competition & Perfect Competition \\
\hline \hline
\end{tabular}

The advantages of the first specification are that it allows us to use quarterly 2 and 3 digit SIC data and makes no assumptions about market structure. The cost is that it imposes a Leontief relationship between $M_{t}$ and $V_{t}$ and a Leontief relationship between capital services and $E_{t}$. The advantages of the second specification are that it allows us to use quarterly 2 digit SIC data and assumes only that labor and electricity markets are perfectly competitive. The cost is that it imposes a Leontief relationship between $M_{t}$ and $V_{t}$. The advantage of the third specification is that it imposes no restrictions on the production technology other than differentiability. The cost is that we can only use annual data and we must assume that all factor markets are perfectly competitive.

We turn to a more detailed discussion of the three technology specifications.

\subsection{Specification 1: The Simplest Structure of Production}

In our simplest production specification, $Y_{t}$ is produced combining value added, $\left(V_{t}\right)$, and materials, $\left(M_{t}\right)$, according to the Leontief production function (1). Basu (1993) has argued persuasively that this Leontief form provides a good approximation to the structure of production in manufacturing, since movements in materials track movements in gross output very closely . An additional motivation for working with this specification, emphasized by Bernanke and Parkinson (1991), is that it allows us to work with industry level gross output data, despite the absence of observations on material inputs.

The value added produced in one hour by one worker is $A_{t} F\left(1, K_{t} / N_{t}\right)$. In setting up our benchmark case, we suppose that the function $F(\cdot)$ is homogeneous of degree one, concave and twice differentiable. The variable $N_{t}$ is the number of time $t$ workers and $A_{t}$ reflects the state of time $t$ technology and other exogenous factors that affect productivity. Since each worker is employed for $H_{t}$ hours, total value added produced by the firm in period $t$ is: ${ }^{5}$

\footnotetext{
${ }^{5}$ This specification of technology is similar to the one used in Chari, Christiano and Eichenbaum (1994).
} 


$$
V_{t}=N_{t} H_{t} A_{t} F\left(1, K_{t} / N_{t}\right)=A_{t} F\left(N_{t} H_{t}, K_{t} H_{t}\right)
$$

So to measure capital services we need to multiply the capital stock by its workweek. In our formulation this coincides with the number of hours that each worker is employed. ${ }^{6}$ This correction for capital utilization is similar to the one originally employed by Solow (1957) which involved multiplying the stock of capital by the employment rate.

The key problem involved in using this production structure is the absence of good direct measures of capital services. Certainly none are available at the quarterly frequency. However, following Griliches and Jorgenson (1967), we can measure these services indirectly via electricity consumption. This strategy has also been employed by Costello (1993) in her study of the properties of the Solow residual in an international context.

Suppose that electricity consumption per machine is proportional to its workweek, $H_{t}$. Then total electricity consumption, $E_{t}$, is given by:

$$
E_{t}=\phi H_{t} K_{t}
$$

Defining total time $t$ hours as $L_{t}=N_{t} H_{t}$, and using equation (1) we obtain

$$
Y_{t}=A_{t} F\left(L_{t}, E_{t} / \phi\right)
$$

From an empirical standpoint, this formula has an important advantage: observations on all of its variables are available at the quarterly frequency for 2 and 3-digit SIC industries. ${ }^{7}$ The disadvantage is that it imposes the strong restriction that the elasticity of electricity use with respect to capital use is equal to one. There are a variety of reasons why this may not be true, such as the existence of overhead capital. The generalized technology discussed

\footnotetext{
${ }^{6}$ Notice that the production function exhibits increasing returns to scale in $N_{t}, H_{t}$ and $K_{t}$. It is standard to assume that there are increasing marginal costs associated with increases in $H_{t}$, say because the rate of depreciation is an increasing function of $H_{t}$. In this case we can optimize with respect to $H_{t}$ and obtain a reduced form production function that is concave in $N_{t}$ and $K_{t}$. See Greenwood, Huffman and Hercowitz (1988).

${ }^{7} \mathrm{~A}$ standard criticism of the use of electricity as a measure of capital utilization is the possible presence of a trend in the electricity-capital ratio. This could reflect a change in the composition of capital away from structures to equipment. We could capture this effect by allowing $\phi$ to be a deterministic function of time. If the function $F(\cdot)$ were Cobb-Douglas, this would simply change the unconditional growth rate of technology.
} 
in section 2.3 relaxes the unit elasticity assumption. In section 5 we discuss how neglecting overhead capital (and labor) can bias our results.

\section{Line Speed and Labor Hoarding}

We now consider the effects of variations in labor effort and in the intensity with which capital is used. Suppose that hourly capital services per worker in equation (3) are $\lambda_{t} K_{t} / N_{t}$, so that the value added produced in one hour by a worker is $A_{t} F\left(1, \lambda_{t} K_{t} / N_{t}\right)$. Here $\lambda_{t}$ denotes the intensity with which capital is used or 'line speed'. Also suppose that electricity consumption per machine is proportional to the effective workweek of the machine, $\phi \lambda_{t} H_{t}$. Then $E_{t}$ is equal to $\phi \lambda_{t} H_{t} K_{t}$ and equation (5) remains unchanged. So, according to this simple formulation, using electricity consumption allows us to measure capital services in a way that is robust to changes in line speed.

To allow for unobserved changes in labor effort, i.e. 'labor hoarding', define the number of efficiency units of labor as $\zeta_{t} H_{t}$. Here $\zeta_{t}$ measures effort per hour. Suppose that total electricity depends on effort so that $E_{t}=\phi \zeta_{t} H_{t} K_{t}$. Then equation (5) becomes:

$$
V_{t}=A_{t} F\left(\zeta_{t} L_{t}, E_{t} / \phi\right)
$$

Notice that $E_{t}$ still measures total capital services. However the production function now involves $\zeta_{t}$, unobserved labor effort. One way to incorporate labor hoarding into the analysis is to specify the costs associated with supplying effort. We could then use the condition that determines the optimal supply of effort to solve for $\zeta_{t}$ as a function of unknown parameters and observable variables. The resulting 'reduced form' production function could be used in empirical work. This is the approach pursued by Burnside, Eichenbaum and Rebelo (1993), Basu and Kimball (1994) and Burnside and Eichenbaum (1994). Here we wish to see how far we can go in explaining the apparent short run increasing returns to labor by controlling for capital utilization while remaining as eclectic as possible about market structure and the determinants of labor supply. Because of this we abstract from variations in effort in our empirical analysis. This will tend to bias our results against the null hypothesis of constant returns to scale. 


\subsection{Specification 2: A Slight Generalization}

The second production specification that we consider is given by

$$
Y_{t}=\min \left(M_{t}, V_{t}^{*}\right),
$$

where $V_{t}^{*}$ is defined as:

$$
V_{t}^{*}=A_{t} F\left(L_{t}, K_{t}^{*}\right) .
$$

Here $K_{t}^{*}$ is given by a CES function of capital and electricity use: ${ }^{8}$

$$
K_{t}^{*}=\left[\mu\left(H_{t} K_{t}\right)^{\rho}+(1-\mu) E_{t}^{\rho}\right]^{1 / \rho}, \quad \rho<1 .
$$

This type of two level production function was first proposed by Sato (1967) and has often been used in the applied general equilibrium literature (see for example Ballard, Fullerton, Shoven and Whalley (1985)). Our assumption that the production function is weakly separable between labor and the two other inputs is consistent with Berndt and Wood's (1979) parameter estimates for a translog cost function fit to a panel of manufacturing industries.

To implement this formulation we need to make use of the optimality condition that determines the firm's demand for electricity. Suppose that the firm acts as a price taker in the market for labor and electricity. Then cost minimization requires that the firm equate the marginal rate of substitution between $N_{t}$ and $E_{t}$ to the relative price of the factors, $W_{t} H_{t} / P_{E t}$. Here $W_{t}$ denotes the real wage rate per hour worked at time $t$ :

$$
\frac{A_{t} F_{2}\left(L_{t}, K_{t}^{*}\right)(1-\mu)\left(K_{t}^{*} / E_{t}\right)^{1-\rho}}{F_{1}\left(L_{t}, K_{t}^{*}\right)}=\frac{P_{E t}}{W_{t}} .
$$

Equation (9) holds regardless of whether the firm is a perfect competitor or not in the goods market. Here $F_{i}$ denotes the partial derivative with respect to the $i^{\text {th }}$ argument of $F$.

In our empirical work we assume that $F(\cdot)$ has a Cobb-Douglas form so that

$$
Y_{t}=A_{t}\left(L_{t}\right)^{\alpha_{1}}\left(K_{t}^{*}\right)^{\alpha_{2}}
$$

Consistent with this notation we do not impose the a priori restriction that the production function is constant returns to scale, i.e. we do not assume that $\alpha_{1}+\alpha_{2}=1$. Given (9)

\footnotetext{
${ }^{8} V_{t}^{*}$ does not correspond to measured value added because it depends upon $E_{t}$. This is immaterial for our empirical work since we use gross output data, rather than value added data.
} 
and (10), gross output can be written as a geometric average of total hours $\left(L_{t}\right)$, energy consumption $\left(E_{t}\right)$ and the price of electricity relative to labor, $p_{E t}$ :

$$
Y_{t}=\left((1-\mu) \frac{\alpha_{2}}{\alpha_{1}}\right)^{\alpha_{2} / \rho} A_{t}\left(L_{t}\right)^{\alpha_{1}+\alpha_{2} / \rho} E_{t}^{\alpha_{2}-\alpha_{2} / \rho} p_{E_{t}}^{-\alpha_{2} / \rho}
$$

Taking first differences and letting lower case letters denote logarithms, we obtain:

$$
\Delta y_{t}=\gamma_{0}+\gamma_{1} \Delta l_{t}+\gamma_{2} \Delta e_{t}+\gamma_{3} \Delta p_{E t}+\epsilon_{t}
$$

Here $\gamma_{0}+\epsilon_{t}$ denotes the growth rate of $A_{t}, \gamma_{1}=\alpha_{1}+\alpha_{2} / \rho, \gamma_{2}=\alpha_{2}-\alpha_{2} / \rho$ and $\gamma_{3}=-\alpha_{2} / \rho$. Our basic production structure coincides with the special case in which the elasticity of substitution between capital and energy is equal to zero $(\rho=-\infty)$. Here (12) becomes ${ }^{9}$

$$
\Delta y_{t}=\gamma_{0}+\alpha_{1} \Delta l_{t}+\alpha_{2} \Delta e_{t}+\epsilon_{t}
$$

We now turn to a brief discussion of the differentiable technology (2).

\subsection{Specification 3: The Differentiable Technology}

Much of the recent literature that uses annual data to study productivity assumes that output is produced according to (2). Taking a first order log linear approximation to this technology yields

$$
\Delta y_{t}=\eta \Delta x_{t}+\epsilon_{t}
$$

where $\eta$ denotes overall returns to scale, $\Delta x_{t}$ is a cost weighted measure of the growth rate of aggregate inputs,

$$
\Delta x_{t}=c_{S t} \Delta s_{t}+c_{L t} \Delta l_{t}+c_{M t} \Delta m_{t}+c_{\mathbf{e}_{t}} \Delta \mathbf{e}_{t}
$$

Here lower case symbols denote logarithms of upper case symbols and $c_{j t}$ denotes the share of factor $j$ in total time $t$ cost.

In sum, our three specifications of technology give rise to three types of relations between factor inputs and output, (12), (13) and (14). But absent further restrictions, these are without empirical content. They hold as identities. To have content, identifying assumptions must be imposed on the stochastic process $\epsilon_{t}$. We turn to this issue in the next section.

\footnotetext{
${ }^{9}$ This relation can be derived directly from (3) under the assumption that $V_{t}$ is Cobb-Douglas in $L_{t}$ and $K_{t} H_{t}$, where the weights do not necessarily add up to one.
} 


\section{Econometric Method and Data}

The fundamental identifying assumption underlying our analysis is that $\epsilon_{t}$ is a stationary technology shock (not necessarily i.i.d.): Suppose that we have observations on a subset of those variables, which, in Hall's (1988) terminology, are known neither to be causes of productivity shifts nor to be caused by productivity shifts. Let $z_{t}$ denote the time $t$ realization of these variables. By assumption

$$
E\left[z_{t} \epsilon_{t}\right]=0
$$

We think of (15) as representing a set of necessary conditions that candidate measures of technology shocks must satisfy. Suppose that the dimension of $z_{t}$ is greater than or equal to the number of parameters in the production technology. Then (15) can be used to estimate the parameters of (12), (13) and (14). We do so via three stage least squares.

In some cases we present 'restricted' estimates, using panels of industry level data. These estimates are obtained by imposing the linear restriction that the parameters of the production technology, with the exception of $\gamma_{0}$, are the same in all industries. The intercept term for each industry is left unrestricted. When the dimension of $z_{t}$ exceeds the number of parameters to be estimated, (15) generates overidentifying restrictions that can be tested. We do so using Hansen's (1982) $J$ test. Parameters restrictions were tested using the Wald statistic discussed in Eichenbaum, Hansen and Singleton (1988).

\section{Choice of Instruments}

We now discuss our choice of instruments, i.e. the observable analogs to the vector $z_{t}$. In principle the vector $z_{t}$ ought to satisfy two criteria. First, the elements of $z_{t}$ should be 'exogenous' in the sense that they are uncorrelated with the growth rate of technology. Second, they should be correlated with economic activity in the industry under consideration, i.e. they ought to be relevant. Finding instruments that satisfy both of these criteria is difficult. Different variables have been used in the literature. Burnside, Eichenbaum and Rebelo (1993) use quarterly innovations to government consumption. Caballero and Lyons (1992), Basu (1993), Bartelsman, Caballero and Lyons (1994) and Basu and Fernald (1994a,b) and Burnside (1994) employ variants of the instruments used in Hall (1988) and 
Ramey (1989). These consist of current and/or lagged values of the annual growth rates of oil prices and real military expenditures as well as the political party of the President.

Shea $(1993 \mathrm{a}, \mathrm{b})$ has criticized the last two of the Hall-Ramey instruments on the grounds that they are not relevant. To make this point, Shea (1993a) regressed the growth rate of industrial production in 20 manufacturing industries on a time trend, seasonal dummies, and current and four lagged values of real military spending, using quarterly, seasonally unadjusted, data over the period 1958-1985. He found that military spending is not statistically relevant for output in any of the industries he looked at. Similar results hold for the political party of the President. According to Shea, results based on irrelevant instruments should not be viewed as 'better' than ordinary least squares estimates. This line of reasoning may provide an additional rationale for the maintained assumption in Shapiro (1993a) that, over the sample period, 1978 - 1988, there were no aggregate technology shocks. Bernanke and Parkinson (1991) make the same assumption using quarterly data over the interwar period to justify the use of ordinary least squares.

In this paper we utilize a different set of instruments. While we do report results for Hall-Ramey type instruments, we also use as instruments lags of the monetary policy shock measures discussed in Christiano, Eichenbaum and Evans (1994). These shock measures are particularly attractive in the present context because they are, by construction, orthogonal to a large set of economic aggregates in the monetary authority's reaction function. Specifically, Christiano, Eichenbaum and Evans (1994) identify monetary policy shocks with the disturbance term in a regression equation of the form:

$$
S_{t}=\psi\left(\Omega_{t}\right)+\varepsilon_{s t}
$$

Here $S_{t}$ is the policy instrument of the monetary authority, $\psi$ is a linear function, $\Omega_{t}$ is the information set available to the monetary authority and $\varepsilon_{s t}$ is a serially uncorrelated shock that is orthogonal to the elements of $\Omega_{t}$. To rationalize interpreting $\varepsilon_{s t}$ as an exogenous policy shock, (16) must be viewed as the monetary authority's rule for setting $S_{t}$. In addition, the orthogonality conditions on $\varepsilon_{s t}$ correspond to the assumption that date $t$ policy shocks do not affect the elements of $\Omega_{t}$. Christiano, Eichenbaum and Evans (1994) derive two measures of policy shocks. These correspond to different specifications of $S_{t}$. In both cases $\Omega_{t}$ is given 
by

$$
\Omega_{t}=\left\{Q_{t}, P_{t}, P C O M_{t}, Q_{t-\tau}, P_{t-\tau}, P C O M_{t-\tau}, F F_{t-\tau}, N B R_{t-\tau}, T R_{t-\tau}: \tau=1, \ldots, 4 .\right\}
$$

Here $Q_{t}, P_{t}, P C O M_{t}, F F_{t}, N B R_{t}$ and $T R_{t}$ denote the time $t$ value of the log of real GDP, the log of the GDP deflator, the log of an index of sensitive commodity prices, the federal funds rate, the log of nonborrowed reserves and the log of time $t$ total reserves, respectively. The two measures of $S_{t}$ are the log level of nonborrowed reserves and the federal funds rate. The corresponding policy shock measures, denoted by $\epsilon_{N B R_{t}}$ and $\epsilon_{F F_{t}}$, correspond to the residual from the OLS regression of the corresponding measure of $S_{t}$ on $\Omega_{t}$, i.e. they are the time $t$ component of $S_{t}$ that is orthogonal to the elements of $\Omega_{t}$.

To see why policy shocks are useful instruments in our context, consider the vector $v_{t}$ consisting of $\epsilon_{N B R_{t}}$ and $\epsilon_{F F_{t}}$. It follows that $v_{t}$ satisfies $E\left[v_{t} \mid \Omega_{t}\right]=0$. We assume that the time $t-\tau$ technology shock for industry $i, \epsilon_{i t-\tau}$, lies in the space spanned by the elements of $\Omega_{t}$, for all $\tau \geq 0$, so that

$$
E\left[v_{t} \epsilon_{i t-\tau}\right]=0 \quad \tau \geq 0 .
$$

Among other things, the statement that $\epsilon_{i t}$ lies in $\Omega_{t}$ embodies the assumption that Christiano, Eichenbaum and Evans (1994) include enough contemporaneous information in the Fed's reaction function so that what they call a policy shock is not in part a reaction to current technology shocks. Under our assumptions it is also true that

$$
E\left[\epsilon_{i t} v_{t-\tau}\right]=0
$$

for all $\tau>0$. The simplest way to see this is to suppose that $\epsilon_{i t}$ has an (invertible) infinite ordered moving average representation $\epsilon_{i t}=a(L) u_{i t}$ where $E\left[u_{i t} \mid \Omega_{t-1}\right]=0$ and $a(L)$ is a square summable polynomial in the lag operator $L$. Then

$$
E\left[\epsilon_{i t} v_{t-\tau}\right]=E\left[\left(a_{0} u_{i t}+a_{1} u_{i t-1}+\cdots+a_{\tau-1} u_{i t-(\tau-1)}\right) v_{t-\tau}\right]+E\left[\left(a_{\tau} u_{i t-\tau}+\cdots\right) v_{t-\tau}\right]
$$

That the first term on the right hand side of this expression is zero follows from $E\left[u_{i t} \mid \Omega_{t-1}\right]=$ 0 . That the second term equals zero follows from (17) and the invariability of $a(L)$. Consequently, (18) holds, so that instrument vectors $z_{t}$ that include current and lagged values of $v_{t}$ satisfy identifying assumption (15). 
An alternative way to rationalize the use of these instruments is to assume that $\epsilon_{i t}$ is an exogenous stochastic process that has an MA(q) time series representation. Then it is appropriate to use $v_{t-\tau}, \tau>q$, as instruments.

The solid lines in figure 1, reproduced from Christiano, Eichenbaum and Evans (1994), depict the estimated time series of $\epsilon_{N B R_{t}}$ and $\epsilon_{F F_{t}}$. Since the policy shock measures are, by construction, serially uncorrelated, they tend to be somewhat noisy. For ease of interpretation we display the centered, three quarter moving average of the shocks. Also, for convenience we include shaded regions, which begin at National Bureau of Economic Research (NBER) business cycle peaks and end at troughs. The estimated standard deviation of $\epsilon_{F F_{t}}$ is 0.79 percent, at an annual rate, while the standard deviation of $\epsilon_{N B R_{t}}$ is 1.61 percent. The two monetary policy shock measures have a correlation of 0.49 .

When we work with quarterly data we consider two specifications of the instrument vector $z_{t}$. The benchmark specification of $z_{t}$ is given by

$$
z_{1 t}=\left\{1, \Delta p_{o, t-1-\tau}, \epsilon_{N B R_{t-2-\tau}}, \epsilon_{F F_{t-2-\tau}} \tau=0, \ldots, 3\right\} .
$$

Here $\Delta p_{o t}$ denotes the growth rate in the price of oil. We lagged the policy shocks measures by two quarters in an attempt to mitigate any spurious correlation between $z_{1 t}$ and $\epsilon_{i t}$ that might arise because of misspecification in the monetary authority's information set. In practice our results were robust to this correction. Our second specification of $z_{t}$, is given by

$$
z_{2 t}=\left\{1, \Delta p_{o, t-\tau}, \Delta g_{t-\tau}, \tau=0, \ldots 7\right\}
$$

Here $\Delta g_{t}$ denotes the time $t$ growth rate in military expenditures. We think of $z_{2 t}$ as corresponding to the Hall-Ramey instruments. In practice, we measure $p_{o t}$ using the quarterly average of the monthly producer price index of crude petroleum (CITIBASE acronym PW561). We measure $g_{t}$ as real Federal government purchases for national defense (CITIBASE acronym GGFENQ).

When we work with annual data we choose as our instruments (i) a constant, (ii) the current and lagged annual growth rate of the price of oil, and (iii) $\epsilon_{N B R_{t-1}}^{A}$ and $\epsilon_{F F_{t-1}}^{A}$ where these are four by one vectors containing the quarterly NBR and FF based policy shock measures from the year $t-1$. We use shock measures that are lagged by a full year to ensure that the instruments do not contain information based on current input or output data. 
To investigate the relevance of our instruments we regress the growth rate of output, the growth rate of hours worked and the growth rate of electricity consumption on three sets of instruments: (i) $z_{1 t}$, (ii) $\left\{\Delta p_{o, t-1-\tau}, \tau=0, \ldots, 3\right\}$, and (iii) $\left\{1, \Delta p_{o, t-\tau}, \Delta g_{t-\tau}, \tau=0, \ldots 3\right\}$. In each case the regression was calculated using data from the aggregate manufacturing sector, the aggregate durable goods sector and the aggregate nondurable goods sector. Table 1 reports the $R^{2}$ associated with these regressions. Notice that the $R^{2}$ associated with the Hall-Ramey type instruments are quite low. They range from a low of .03 when the growth rate of electricity consumption in the durables sector is used as the dependent variable to a high of .10 when we used the growth rate of output in the manufacturing or durable goods sectors as the dependent variable. Comparable $R^{2}$ emerge with $\left\{\Delta p_{o, t-1-\tau}, \tau=0, \ldots, 3\right\}$. In contrast, our benchmark instrument list does much better. Here the $R^{2}$ range from a low of .24 when the growth rate of electricity consumption in the nondurables sector is used as the dependent variable to a high of .42 when we used the growth rate of output in the manufacturing sector as the dependent variable. Evidently lagged values of $\epsilon_{N B R_{t}}$ and $\epsilon_{F F_{t}}$ contain substantial amounts of information regarding the different measures of economic activity that we consider, i.e. they are relevant.

In general, the asymptotic distribution of the technology parameters are affected by the fact that $\epsilon_{N B R_{t}}$ and $\epsilon_{F F_{t}}$ are generated regressors. However, this is not the case in our application as long as the growth rate in technology is an exogenous $M A(q)$ process and $z_{1 t}$ includes only estimated values of $\epsilon_{N B R_{t}}$ and $\epsilon_{F F_{t}}$ that are lagged by at least q periods. ${ }^{10}$ To see this write regression equation (16) as

$$
Z_{t}=\beta^{\prime} X_{t}+\epsilon_{S t}
$$

Denote the estimated values of $\epsilon_{S t}$ as $\hat{\epsilon}_{S t}$. Consider a vector of instruments, $\widehat{V}_{t-\tau}$, that includes values of $\hat{\epsilon}_{S t}$, lagged at least $\tau>q$ periods. For simplicity sake, we consider the case in which the number of instruments equals the number of parameters to be estimated. Suppose that we estimate the parameters $\gamma$ in the relationship

$$
W_{t}=\gamma^{\prime} D_{t}+e_{t}
$$

\footnotetext{
${ }^{10}$ We thank Mark Watson for pointing this out to us.
} 
via an instrumental variables procedure that imposes the orthogonality restrictions

$$
E\left[\widehat{V}_{t-\tau} e_{t}\right]=0
$$

Then

$$
\sqrt{T}(\widehat{\gamma}-\gamma)^{\prime}=\frac{\frac{1}{\sqrt{T}} \sum_{t=1}^{T}\left[e_{t} \widehat{V}_{t-\tau}^{\prime}\right]}{\frac{1}{T} \sum_{t=1}^{T}\left[D_{t} \widehat{V}_{t-\tau}^{\prime}\right]}
$$

Since $\widehat{V}_{t-\tau}=V_{t-\tau}+(\widehat{\beta}-\beta)^{\prime} X_{t-\tau}$, it follows that

$$
\frac{1}{\sqrt{T}} \sum_{t=1}^{T}\left[e_{t} \hat{V}_{t-\tau}^{\prime}\right]=\frac{1}{\sqrt{T}} \sum_{t=1}^{T}\left[e_{t} V_{t-\tau}^{\prime}\right]+\sqrt{T}(\widehat{\beta}-\beta)^{\prime}\left[\frac{1}{T} \sum_{t=1}^{T}\left(X_{t-\tau} e_{t}\right] .\right.
$$

As long $\tau>q, T^{-1} \sum_{t=1}^{T}\left[X_{t-\tau} e_{t}\right]$ converges in probability to zero. Next note that $T^{-1} \sum_{t=1}^{T}\left[D_{t} \widehat{V}_{t-\tau}^{\prime}\right]$ $=T^{-1} \Sigma_{t=1}^{T}\left[D_{t} V_{t-\tau}^{\prime}\right]_{t}+(\widehat{\beta}-\beta) T^{-1} \Sigma_{t=1}^{T}\left[D_{t} X_{t-\tau}\right]$, so that $T^{-1} \sum_{t=1}^{T}\left[D_{t} \widehat{V}_{t-\tau}^{\prime}\right]$ converges in probability to the same matrix as $T^{-1} \Sigma_{t=1}^{T}\left[D_{t} V_{t-\tau}^{\prime}\right]$. It follows that the asymptotic distribution of $\sqrt{T}(\widehat{\gamma}-\gamma)^{\prime}$ is unaffected by the fact that we must estimate $V_{t-\tau}$.

\subsection{Data}

Our empirical work utilizes data from a variety of sources. All data referred to in this subsection are seasonally adjusted. We indicate the CITIBASE acronym for each variable in brackets.

\section{Economy Wide Input and Output Data}

In some of our empirical work we employ economy wide aggregates. Here our measure of output is quarterly real GDP (GNPQ) over the sample period 1972:2 - 1992:4. Our measure of hours worked is the quarterly average of monthly total employee - hours in nonagricultural establishments (LPMHU). We considered two measures of the quarterly growth rate in the real capital stock. The first is taken from Hall (1994). The second is an updated version (available only through 1988:4) of the measure discussed in Christiano (1988). ${ }^{11}$ Our measure of aggregate electricity consumption is a quarterly average of a monthly index of total electrical power usage in the industrial sector (manufacturing plus mining plus utility industries). ${ }^{12}$ When dealing with economy wide aggregates we measure

\footnotetext{
${ }^{11}$ We thank Jonas Fisher for making this data available to us.

${ }^{12}$ We thank Joe Beaulieu for making this data available to us in machine readable form. This raw data is published on a monthly basis in Industrial Production, Federal Reserve Statistical Release G.12.3.
} 
the relative price of electricity using the quarterly average of the producer price index for electric power (PW054) and quarterly compensation per hour in the non farm business sector (LBCPU).

\section{Manufacturing Sector Input and Output Data}

We measure quarterly labor input at the 2 digit SIC level using quarterly averages of monthly production worker hours. For each 2 digit industry this measure is constructed as the product of two time series, average weekly hours of production workers (LPHRXX) and production workers on nonagricultural payrolls (LPPXX). Here XX refers to the relevant 2 digit SIC code. For aggregate manufacturing it is also possible to obtain data on a broader measure of labor input, total hours of all persons, worked by all employees (LMNM). This broader measure of labor input is not available at the 2 digit SIC level. To justify abstracting from non-production workers on the basis of the simple model of section 2 we need to assume that their input is used in fixed proportions with value added. If this Leontief assumption does not hold, the interpretation of our results continues to be valid only if the correlation between non-production hours and production hours is one.

Annual labor input measures correspond to the annual averages of the monthly data. All of the data are available over the period 1972:1-1992:4. Corresponding 3 digit level data for the sample period 1977:1 - 1992:4 were obtained from the Board of Governors.

Electricity consumption was measured as kilowatts of electricity used at the 2 digit SIC level. These data were obtained from the Board of Governors. The two digit SIC level data are available over the period 1972:2 - 1992:4, while the 3 digit SIC level data are available over the sample period 1977:1-1992:4. Quarterly and annual data correspond to averages of the underlying monthly data.

Obtaining quarterly measures of industry level output is more difficult than obtaining the corresponding input measures. The Federal Reserve Board uses three sources of data to construct the industrial production index: measures of physical product, kilowatt hours of electricity, and production worker hours. The weight on each of these underlying sources of information depends on the industry in question. Averaging over all 2 digit SIC manufacturing industries, roughly $43 \%, 31 \%$ and $26 \%$ of the output index is based on measures of 
physical product, kilowatt hours and production worker hours data, respectively. Note that the Board does not use a simple, mechanical rule for inferring output from inputs. Instead it estimates output using time varying production factor coefficients. If we conceive of the Board as producing an optimal prediction of output given the information at its disposal, it is reasonable to use the Board data on output. ${ }^{13}$ Still, we would be nervous about basing inference entirely on this data set.

Fortunately there are a number of ways to assess the robustness of our results to the use of alternative data sources. First, we exploit the fact that there are many 3 digit SIC industries where the output index produced by the Board is strictly based on physical product. We constructed a database with the subset of these 3 digit industries for which we could obtain matching labor input and electricity use over the period 1977:1 - 1992:4. The net result was a panel of 26 three digit SIC industries. These are listed in Appendix A, along with the three digit SIC codes and the corresponding 2 digit SIC industries. Second, we repeat our analysis using annual data. At the annual frequency, the Board's measure of output is not based on input data. This is because data from various censuses provide actual production data for most industries. Therefore the problem of inferring output from inputs is almost entirely an issue for within year variation of industrial output.

\section{Empirical Results}

\section{Some Basic Facts}

We begin our analysis with a brief review of some basic facts. Figure 2 displays the quarterly growth rates of real GDP $\left(\Delta y_{t}\right)$, economy wide hours worked $\left(\Delta l_{t}\right)$ and aggregate industrial electricity consumption $\left(\Delta e_{t}\right)$. It is clear that $\Delta e_{t}$ is highly correlated with both $\Delta y_{t}$ and $\Delta l_{t}$, even though at the aggregate level it is difficult to obtain a measure of electricity consumption that matches the output concept. The high correlation between these aggregates is documented in the following table which presents the unconditional correlations between $\Delta y_{t}, \Delta l_{t}, \Delta e_{t}$ and the growth rate in our measure of capital, $\Delta k_{t}$. In contrast to

\footnotetext{
${ }^{13}$ See Miron and Zeldes (1989) for a discussion of different models of measurement error in this context.
} 
$\Delta e_{t}, \Delta k_{t}$ is basically uncorrelated with $\Delta y_{t}$ and $\Delta l_{t}$ (as well as $\Delta e_{t}$ ). ${ }^{14}$ This is why analysts have traditionally found that capital plays no role in explaining cyclical fluctuations in output - existing measures of capital are poor measures of capital services, at least at cyclical frequencies.

\begin{tabular}{||c|cccc||}
\hline \hline \multicolumn{5}{||c|}{ Correlations: Economy Wide } \\
\hline \multirow{3}{*}{$\Delta y_{t}$} & $\Delta y_{t}$ & $\Delta l_{t}$ & $\Delta e_{t}$ & $\Delta k_{t}$ \\
\cline { 2 - 5 }$h_{t}$ & .0 & .82 & .72 & .09 \\
$\Delta e_{t}$ & .72 & 1.0 & .73 & .31 \\
$\Delta k_{t}$ & .09 & .31 & .07 & .07 \\
\hline \hline
\end{tabular}

Figures 3 and 4 are the analogs to figure 2 except they are based on quarterly and annual manufacturing data. Figures 5 and 6 display, in a graphical manner, the quarterly and annual correlations between $\left(\Delta y_{t}\right.$ and $\left.\Delta l_{t}\right),\left(\Delta y_{t}\right.$ and $\left.\Delta e_{t}\right)$, and $\left(\Delta l_{t}\right.$ and $\left.\Delta e_{t}\right)$ for the individual 2 digit SIC industries underlying the aggregate manufacturing data. The following table summarizes the correlations between $\Delta y_{t}, \Delta l_{t}$ and $\Delta e_{t}$ for the manufacturing sector as a whole.

\begin{tabular}{||c|cccccc||}
\hline \hline \multicolumn{7}{||c||}{ Correlations: Manufacturing Sector } \\
\hline & Quarterly & \multicolumn{3}{|c|}{ Annual } \\
\hline & $\Delta y_{t}$ & $\Delta l_{t}$ & $\Delta e_{t}$ & $\Delta y_{t}$ & $\Delta l_{t}$ & $\Delta e_{t}$ \\
\cline { 2 - 7 }$\Delta y_{t}$ & 1.0 & .94 & .80 & 1.0 & .95 & .88 \\
$\Delta l_{t}$ & .94 & 1.0 & .81 & .95 & 1.0 & .94 \\
$\Delta e_{t}$ & .80 & .81 & 1.0 & .88 & .94 & 1.0 \\
\hline \hline
\end{tabular}

A number of points are worth making here. First, as in the aggregate data, $\Delta e_{t}$ is highly correlated with $\Delta y_{t}$ and $\Delta l_{t}$. Indeed, the correlation is even more pronounced in the manufacturing data. This may reflect the fact that our measure of $e_{t}$ corresponds exactly to the manufacturing sector. Second, the quarterly and annual correlations are very similar. If anything $\Delta e_{t}$ and $\Delta l_{t}$ are slightly less correlated with output at the quarterly level. This is very comforting given possible concerns about the use of input data in the procedure used by the Board to construct some of the quarterly output data. Recall that while these concerns are relevant for the quarterly data, they are not relevant for the annual data. So the basic

\footnotetext{
${ }^{14}$ This is also true if we redo the analysis over the sample period 1972:1-1988:4 using the measure of capital discussed in Christiano (1988).
} 
fact which drives our inferences - namely that $\Delta e_{t}$ comoves positively with $\Delta y_{t}$ and $\Delta l_{t}$ cannot be dismissed as an artifact of the way the output data are constructed.

A different way to see this is to consider the correlations between $\left(\Delta y_{t}\right.$ and $\left.\Delta l_{t}\right),\left(\Delta y_{t}\right.$ and $\left.\Delta e_{t}\right)$, and $\left(\Delta l_{t}\right.$ and $\left.\Delta e_{t}\right)$ for the individual 3 digit SIC code industries where the Board's measure of output data is not constructed with the aid of any input data. These are displayed in figure 7. Notice that while there are interesting differences between the industries, in the vast majority of cases $\Delta e_{t}$ displays a sharp positive correlation with $\Delta y_{t}$ and $\Delta l_{t}$.

Next we consider the cyclical properties of a different measure of capital services: the workweek of capital, $w k_{t}$. Shapiro (1993a), among others, has suggested that a measure of $w k_{t}$ might be useful in correcting capital stock data for cyclical variations in capital services. To pursue point, we obtained the measure of $w k_{t}$ used by Shapiro (1993a). This consists of an updated version of the series published by Foss (1981). The data are annual, with each observation corresponding to the fourth quarter workweek of capital. The sample period is 1976:4 - 1988:4. The following table summarizes the correlations between $\Delta y_{t}, \Delta l_{t}, \Delta e_{t}$, and $\Delta w k_{t} \cdot{ }^{15}$

\begin{tabular}{||l|ccll||}
\hline \hline \multicolumn{5}{||c||}{ Measured Work Week of Capital } \\
\hline \multirow{3}{*}{$\Delta y_{t}$} & $\Delta y_{t}$ & $\Delta l_{t}$ & $\Delta e_{t}$ & $\Delta w k_{t}$ \\
\cline { 2 - 5 }$\Delta l_{t}$ & 1.0 & .95 & .88 & .88 \\
$\Delta e_{t}$ & .95 & 1.0 & .90 & .89 \\
$\Delta w k_{t}$ & .88 & .90 & 1.0 & .74 \\
\hline \hline
\end{tabular}

Notice that $\Delta w k_{t}$ displays a strong positive correlation with $\Delta y_{t}, \Delta l_{t}$ and $\Delta e_{t}$. We take this fact to be supportive of our basic hypothesis that capital utilization rates are procyclical. ${ }^{16}$

We conclude this subsection by briefly documenting the apparent 'short run increasing returns to scale' or SRIRL puzzle. All the results that we report were obtained using the GMM procedure and the instrument list $z_{1 t}$ discussed in section 3. The following table presents the points estimates of $\eta_{1}$ that result from estimating the relationship $\Delta y_{t}=\eta_{0}+$ $\eta_{1} \Delta l_{t}+\epsilon_{t}$ using aggregate and manufacturing sector data.

\footnotetext{
${ }^{15}$ All growth rates were calculated on a fourth quarter to fourth quarter basis.

${ }^{16}$ We also computed the correlations between the growth rate of total capital services, $\left(k_{t} \cdot w k_{t}\right)$ and $\left(\Delta y_{t}\right.$, $\left.\Delta l_{t}, \Delta e_{t}\right)$. These are similar to the ones between $w k_{t}$ and $\left(\Delta y_{t}, \Delta l_{t}, \Delta e_{t}\right)$.
} 


\begin{tabular}{|c|c|c|c|c|c|c|c|c|}
\hline \multicolumn{9}{|c|}{ Returns to Labor } \\
\hline \multirow[b]{3}{*}{$\eta_{1}$} & Economy & Vide & & Manufactı & & & & \\
\hline & Total Hrs. & Prod. & Worker Hrs. & Total Hrs. & Prod. & Worker Hrs. & Durables* & Nondurables* \\
\hline & $\begin{array}{l}1.21 \\
(.13)\end{array}$ & $\begin{array}{l}96 \\
(.09)\end{array}$ & & $\begin{array}{l}1.25 \\
(.08)\end{array}$ & $\begin{array}{l}97 \\
(.06)\end{array}$ & & $\begin{array}{l}92 \\
(.06)\end{array}$ & (98) \\
\hline
\end{tabular}

Notice that when total hours worked are used to construct $\Delta l_{t}, \eta_{1}$ is estimated to be significantly greater than one. When production worker hours are used, $\eta_{1}$ is estimated to be approximately one. This is true, regardless of whether we work with aggregate data, manufacturing data, durables goods data or nondurables goods data. SRIRL appears to be alive and well, even with our instruments.

The following table presents the point estimates of $\eta_{1}$ that result from estimating the relationship $\Delta y_{t}=\gamma_{0}+\gamma_{2} \Delta e_{t}+\epsilon_{t}$.

\begin{tabular}{|c|c|c|c|c|}
\hline \multicolumn{5}{|c|}{ Returns to Electricity } \\
\hline \multirow[b]{3}{*}{$\eta_{2}$} & Economy Wide & Mant & acturing & \\
\hline & & Total & Durables & Nondurables \\
\hline & $\begin{array}{r}49 \\
(.07)\end{array}$ & $\begin{array}{l}1.15 \\
(.14)\end{array}$ & $\begin{array}{r}83 \\
(.09)\end{array}$ & $\begin{array}{l}.92 \\
(.19)\end{array}$ \\
\hline
\end{tabular}

Notice that, for the manufacturing sector, measuring factor input by electricity alone or hours alone yields very similar results. Indeed we even get 'short run increasing returns to electricity'. The estimated value of $\eta_{2}$ is positive but smaller for the economy wide case. Presumably this reflects the fact that we do not have as good a measure of electricity use for the economy wide data.

\section{CES Versus Leontief}

The previous subsection documented the basic fact that the growth rate of electricity consumption is highly correlated with the growth rates of hours worked and output. We now consider how this fact affects technology parameter estimates. Table 2 reports the results of estimating the parameters of the technology specification given by (6) - (7) which allows for substitution between capital services and electricity. The first column presents economy wide results, while the second column presents results pertaining to the total manufacturing sector. The third column presents results obtained imposing the restriction that the technology 
parameters are the same in all 2 digit SIC industries. The fourth and fifth columns are the analogs to the third column except that they pertain to the durable and nondurable goods industries. The row $J_{1}$ reports the probability value associated with the statistic for testing the overidentfying restrictions of the model. The row $J_{2}$ reports the probability value associated with the statistic for testing the hypothesis of constant returns to scale, $\alpha_{1}+\alpha_{2}=$ 1. The last three rows report different statistics pertaining to the average 'technology shocks' $\epsilon_{t}$. For restricted panel runs, the reported statistic regarding $\epsilon_{t}$ pertains to the average value of the industry specific statistic. For example, $\sigma_{\epsilon}$ corresponds to the average value of the standard deviation of $\epsilon_{t}$ across the different industries.

The key result is that across all of the cases considered, the estimated value of $\sigma$, the elasticity of substitution between the workweek of capital and electricity, is positive but very small. Specifically, it ranges from a low of .03 for the aggregate manufacturing sector to a high of .30 for the nondurables goods sector. In no case can we reject the null hypothesis that $\sigma=0$. This case corresponds to the Leontief specification given by (3)..$^{17}$

A different way to assess the Leontief specification is to investigate the empirical relationship between the growth rate of electricity and the growth rate of capital services, as measured by the growth rate of the product of the workweek of capital $\left(\Delta w k_{t}\right)$ and the stock of capital $\left(k_{t}\right)$. The following Table reports the results of estimating the relationship

$$
\Delta e_{t}=\beta\left[\Delta w k_{t}+\Delta k_{t}\right]
$$

using our three stage least squares procedure in conjunction with instrument list $z_{1 t}$.

\begin{tabular}{||l|lll||}
\hline \hline \multirow{3}{*}{$\beta$} & Aggregate Manufacturing & Aggregate Durables & Aggregate Non Durables \\
\cline { 2 - 4 } & 1.23 & 1.77 & .53 \\
& $(0.55)$ & $(0.77)$ & $(0.35)$ \\
\hline \hline
\end{tabular}

Notice that, in no case, can we reject the null hypothesis, $\beta=1$. light of this result and our previous findings regarding $\sigma$, through much of what follows, we impose the restriction that electricity use is proportional to the workweek of capital. Table 2 contains results generated

\footnotetext{
${ }^{17}$ It is interesting to contrast the restricted point estimates of $\alpha_{1}, \alpha_{2}$ and $\sigma$ in the manufacturing industries $(.71, .30$, and .03$)$ with the unrestricted point estimates for the underlying industries. One way to summarize the unrestricted estimates is to focus on their median. The median point estimates of $\alpha_{1}, \alpha_{2}$ and $\sigma$ are .60 .38 and .16 . The associated median standard errors are $.37, .35$ and .55 . Evidently, the qualitative nature of inference here is not affected by imposing the (false) restriction that the 2 digit industries have the same technology coefficients.
} 
without imposing that restriction. So the reader can verify that none of the conclusions discussed in the text are affected by the imposition of that restriction.

In the remainder of this section we address five key questions: (1) Does SRIRL vanish once capital services are measured by electricity consumption? (2) Are capital services productive when measured by electricity consumption? (3) Is there evidence against the hypothesis of constant returns to scale? (4) Is there evidence against the overidentifying restrictions of our model? and (5) What can we say about the properties of technology shocks? We address these questions at three levels of aggregation: economy wide data, 2 digit SIC code level data and 3 digit SIC code level data.

\section{Economy Wide Data}

Table 3 reports the results of estimating the model using economy wide data. The first column reports results obtained using two different measures of the capital stock. The third column reports results obtained measuring capital services by electricity consumption. A number of results emerge here. First, when we use the capital stock data, SRIRL emerges, i.e. $\alpha_{1}$ is estimated to be greater one. In addition, the estimated value of $\alpha_{2}$ is negative and insignificantly different from zero. In sharp contrast, when we measure capital services by electricity use, the SRIRL phenomenon disappears and capital services enters significantly into the production technology. Second, there is no evidence against the hypothesis of constant returns to scale. Finally, according to the $J_{1}$ statistic there is no evidence against the model's overidentifying restrictions.

Using electricity consumption as a measure of capital services has important implications

for the statistical properties of the technology shocks. As a benchmark, suppose we simply set $\alpha_{1}=.64$ and $\alpha_{2}=.36$. Using the stock of capital and electricity consumption as measures of capital services we obtain

\begin{tabular}{||l|ll||}
\hline \hline \multirow{3}{*}{$J_{1}$} & $\Delta S_{t}=\Delta K_{t}$ & $\Delta S_{t}=\Delta e_{t}$ \\
\cline { 2 - 3 }$\sigma_{\epsilon} / \sigma_{\Delta Y}$ & .015 & .42 \\
$\rho_{\epsilon \Delta Y}$ & .67 & .77 \\
\hline \hline
\end{tabular}

respectively. Notice that with the stock of capital measure, there is substantial evidence against the model's overidentifying restrictions. There is virtually no evidence against these 
restrictions when capital services are measured using electricity. Perhaps more importantly, with the electricity measure and these parameter values, the technology shocks are virtually uncorrelated with the growth rate of output. Moving to the estimated values of $\alpha_{1}(.54)$ and $\alpha_{2}$ (.30) lowers $\sigma_{\epsilon} / \sigma_{\Delta y}$ and raises $\rho_{\epsilon \Delta y}$ somewhat (see Table 3). But even there $\rho_{\epsilon \Delta y}$ is only equal to .31. This small correlation seems very difficult to reconcile with existing RBC models that are driven primarily by technology shocks. Finally, it is worth emphasizing that our electricity based technology shocks are much less volatile and substantially less correlated with output than those emerging from the measures of output, hours worked and stock of capital that are typically used in the RBC literature. ${ }^{18}$

\section{Manufacturing Sector Data}

Table 4 reports results based on the 2 digit SIC data. Columns labeled 'Aggregate' pertain to aggregate manufacturing data while the columns labeled 'Restricted' refer to results obtained using the panel on 2 digit SIC industries. Results are reported for both quarterly and annual data.

Consider the quarterly results. First, for aggregate manufacturing, the point estimates of $\alpha_{1}$ and $\alpha_{2}$ are .69 and .31, respectively. The corresponding restricted panel point estimates are .64 and $.37 .^{19}$ These estimates are remarkably close to national income based estimates of labor and capital shares obtained using a constant returns to scale Cobb-Douglas production function (see for example Christiano and Eichenbaum (1992)). Second, the $J_{2}$ statistics reveal virtually no evidence against the hypothesis of constant returns to scale. Third, the overidentifying restrictions associated with the aggregate model can be rejected at the $1 \%$ significance level. However, there is very little evidence against these restrictions for the restricted panel. Fourth, comparing our economy wide based estimates of $\sigma_{\epsilon} / \sigma_{\Delta Y}$ and $\rho_{\epsilon \Delta Y}$ (.60 and .31) with those reported in Table 4 (.37 and .21), we see that these fall as we move to the aggregate manufacturing sector. However, we are hesitant to make too much of this

\footnotetext{
${ }^{18}$ For example, suppose we use Christiano's (1988) measure of capital, hours worked and output. In addition set $\alpha_{1}=.655$ and $\alpha_{2}=.345$, the values estimated in Christiano and Eichenbaum (1992). The resulting point estimates of $\sigma_{\epsilon}$ and $\sigma_{\epsilon} / \sigma_{\Delta y}$ are .0114 and 1.05 , respectively. The correlation coefficient between $\epsilon_{t}$ and $\Delta Y_{t}, \rho_{\epsilon \Delta Y}$, is approximately equal to .80 .

${ }^{19}$ The median unrestricted point estimates of $\alpha_{1}$ and $\alpha_{2}$ across the 2 digit industries are .54 and .38. The corresponding median standard errors are .20 and .22 .
} 
fact because our estimates of $\sigma_{\epsilon} / \sigma_{\Delta Y}$ and $\rho_{\epsilon \Delta Y}$ rise to .63 and .54 , respectively when we work with the restricted panel data. But even these estimates are smaller than those used in the RBC literature.

The key finding with the annual data is that the results are quite similar to those obtained with the quarterly data. There is some difference in the point estimates associated with the restricted panel. ${ }^{20}$ This sensitivity is also revealed in the portion of Table 4 reporting annual results for the durable and nondurable good sector. This point aside, inference seems robust. Specifically, (1) there is no evidence of SRIRL, (2) there is no evidence against the hypothesis of constant returns to scale, (3) there is little evidence against the overidentifying restrictions of the model, and (4) there is overwhelming evidence that capital services, as measured by electricity, are an important factor of production. The fact that inference is robust to the use of annual data is particularly comforting because annual output data is not constructed using information on factor inputs. As a further check on the robustness of the 2 digit SIC results, Appendix A reports results obtained by omitting 2 digit SIC industries in which a particularly large proportion of the output index reported by the Board is based on input data.

\section{Digit SIC Sector Data}

Table 5 reports results obtained using our 3 digit SIC data set. Recall that this data set consists of 3 digit industries for which there are direct measures of physical output. The columns labeled 'Restricted' refer to results generated under the restriction that the coefficients $\alpha_{1}$ and $\alpha_{2}$ are the same in all of the industries we looked at. The columns labeled 'Unrestricted' report results generated from the corresponding unrestricted runs. Specifically, we report the median point estimate of $\alpha_{1}$ and $\alpha_{2}$ as well as the corresponding median standard errors. In addition we report the median probability of the $J_{2}$ statistic as well as the median point estimates of $\sigma_{\epsilon}, \sigma_{\epsilon} / \sigma_{\Delta y}$ and $\rho_{\epsilon} \Delta y$. The probability value for the $J_{1}$ statistic refers to the overidentifying restrictions associated with the entire system of unrestricted runs.

\footnotetext{
${ }^{20}$ The median point estimates of $\alpha_{1}$ and $\alpha_{2}$ obtained using the unrestricted annual 2 digit using data are .80 and .17 , respectively, with corresponding standard errors of .13 and .15 .
} 
The key features to note here are as follows. First, as above, there is no evidence for either SRIRL or increasing returns to scale. If anything there is some evidence of decreasing returns, but only for the restricted specification where we do not distinguish between durable and nondurable goods. This specification aside, we find very little evidence against the hypothesis of constant returns to scale. Second, as was the case with our other data sets, we find a substantial role for capital services, as measured by electricity, in producing output. Third, there is virtually no evidence against the overidentifying restrictions imposed by the model. This is true regardless of whether we work with the entire panel or condition on durables and nondurables goods industries. Finally, we find that the estimated values of $\sigma_{\epsilon} / \sigma_{\Delta y}$ and $\rho_{\epsilon \Delta y}$ are somewhat larger than those emerging from the manufacturing and economy wide data. Still, these estimates are substantially smaller than those used in the RBC literature. We conclude that the main findings obtained with the aggregate and 2 digit SIC data are confirmed by the 3 digit SIC data.

We now briefly comment on the results of working with the alternative instrument set, $z_{2 t}$. Table 6 reports a subset of the results we obtained with the Hall-Ramey type instruments. Specifically, we display results for the restricted 2 digit and 3 digit SIC panels as well as the median estimates from the corresponding unconstrained specifications. The key point to note is the robustness of our results to the change in instruments.

\section{The Differentiable Technology}

We conclude this section by reporting results obtained from estimating the returns to scale parameter $\eta$ in the production technology given by (2). We estimated $\eta$ using three measures of the growth rate of capital services, $\Delta S_{t}$. These measures are the growth rate in the stock of capital, the growth rate of electricity and the growth rate in the workweek of capital times the stock of capital. The corresponding sample periods, which were dictated by data availability, are 1961 - 1989, 1973-1989, and 1977 - 1988, respectively. In all cases the data correspond to fourth quarter to fourth quarter growth rates. The instrument list is given by $z_{1 t}$. Results for aggregate manufacturing, durable and nondurable goods are reported in Table 7 . 
The key results can be summarized as follows. First, for aggregate manufacturing and durable goods, the estimated value of $\eta$ is highest when $\Delta S_{t}$ is measured by $\Delta K_{t}$. Moving to electricity or workweek of capital based measures of $\Delta S_{t}$ results in smaller $\eta$. With these measures we cannot reject the hypothesis of constant returns to scale. If anything, there is some mild evidence of decreasing returns to scale in the nondurable goods industries. Third, in all cases the estimated shocks to technology and their correlation with the growth rate of output are much smaller than those used in the RBC literature.

Viewed as a whole we conclude that inference about returns to scale is quite robust across the three specifications of technology that we considered. There just is not much evidence in our data sets against the hypothesis of constant returns to scale.

\section{Shortcomings of the Analysis}

In this section we discuss how the presence of capital goods that do not use electricity, overhead labor and capital, and multiple production shifts could affect the interpretation of our results.

\subsection{Non-Production Workers and Overhead Costs}

So far we have stressed mismeasurement of capital services as the main source for the apparent short run increasing returns to labor. An alternative and perhaps complementary explanation for this phenomenon is the existence of large overhead costs. To see this, suppose that the production function is of the form:

$$
Y_{t}=A_{t}\left(L_{t}-\varphi\right)^{\alpha_{1}} K_{t}^{\alpha_{2}}
$$

Here $\varphi$ represents overhead hours. An infinitesimal increase in hours worked due to a demand shock generates a change in labor productivity equal to:

$$
\frac{d\left(Y_{t} / L_{t}\right)}{d L_{t}}=\frac{Y_{t}}{L^{2}}\left[\left(\alpha_{1}-1\right) L+\varphi\right] .
$$

Suppose $\alpha_{1}<1$. Then, absent overhead costs $(\varphi=0)$, this derivative is negative, suggesting that labor productivity ought to be countercyclical in a model driven primarily by demand shocks. However, for $\varphi>\left(1-\alpha_{1}\right) L$, this derivative will be positive. This could, 
in principle, rationalize procyclical productivity even in a model driven by demand shocks. However a simple back-of-the-envelope calculation suggests that the required overhead costs must be large. If $\alpha_{1}$ is roughly equal to $.65, \frac{d\left(Y_{t} / L_{t}\right)}{d L_{t}}$ will be positive only if overhead costs represent $35 \%$ of $L_{t}$.

Even if overhead costs are not this large, the fact that we have neglected them could bias our econometric results. Taking a first order log-linear approximation to the production function (19) and first differencing yields the following expression for the growth rate of output

$$
\Delta y_{t}=\Delta a_{t}+\alpha_{1} \frac{L}{L-\varphi} \Delta l_{t}+\alpha_{2} \Delta k_{t}
$$

As before lower case letters denote the logarithm of the corresponding variables. Also $L$ represents the point around which we linearize (19). The key point is that, as long as $\varphi>0$, the sum of the coefficients on $\Delta l_{t}$ and $\Delta k_{t}$, will not equal one even if $\alpha_{1}+\alpha_{2}=1$. This is because the coefficient on $\Delta l_{t}$ is biased upwards, away from $\alpha_{1}$. However this does not imply that our estimate of local returns to scale, as defined by Rotemberg and Woodford (1995), is biased. These authors define local returns to scale for a production function $F(K, L)$ to be

$$
\nu=\frac{K F_{1}(K, L)+L F_{2}(K, L)}{F(K, L)} .
$$

For the function $F(\cdot)$ given by (19), $\nu$ is given $\alpha_{1} \frac{L}{L-\varphi}+\alpha_{2}$. So in this case, our estimate of the sum of the coefficients on $\Delta k_{t}$ and $\Delta l_{t}$ is a consistent estimate of $\nu$.

On a priori grounds, it might be reasonable to assume that overhead costs are more important for supervisory labor than for production workers. To the extent that this is true, estimates of the coefficient on $\Delta l_{t}$ should be higher when that variable is measured as total hours worked rather than total production worker hours. Because of data constraints we can only pursue this idea for the aggregate manufacturing sector. When we reestimate (13) with this measure of $\Delta l_{t}$ and electricity based measure of capital services, the point estimates of the coefficients on $\Delta l_{t}$ and $\Delta e_{t}$ are .82 and .36. The corresponding standard errors are .26 and .20 , respectively. Recall from table 2 that the analogue estimates obtained using total production worker hours as the measure of $\Delta l_{t}$ are .69 and .31 . The corresponding standard errors are .16 and .17 , respectively. The fact that the point estimate of the coefficient on $\Delta l_{t}$ 
is higher in the case of total worker hours is consistent with the presence of more overhead costs for supervisory workers. However, we cannot reject the hypothesis that the coefficients are actually the same in the two cases. So it is possible that there are important overhead costs associated with labor, and that these might be contribute to the procyclicality of labor productivity. But the empirical case that these types of costs are more important for supervisory workers than for production workers is weak.

\subsection{Issues Regarding the Stock of Capital}

Supposing that there is overhead capital which enters the production in a manner similar to overhead labor. Then, proceeding as above, it is straightforward to show that the coefficient on the change in $\Delta k_{t}$, will be biased upwards, away from $\alpha_{2}$. As above, this will not induce a bias in our estimate of local returns to scale, $\nu$.

Next we consider the case in which only a subset of the capital stock employs electricity. Specifically, consider our simplest specification of the production technology (3). Suppose that $K_{t}=K_{1 t}+K_{2 t}$, so that

$$
Y_{t}=A_{t}\left(L_{t}\right)^{\alpha_{1}}\left(K_{1 t} H_{t}+K_{2 t} H_{t}\right)^{\alpha_{2}}
$$

where $H_{t}$ denotes time $t$ hours of work per worker. Also suppose that electricity use is given by

$$
E_{t}=\phi K_{1 t} H_{t}
$$

and that $K_{2 t}$ does not require the use of electricity. Taking a log linear approximation to (22) we obtain,

$$
\Delta y_{t}=\Delta a_{t}+\alpha_{1} \Delta l_{t}+\alpha_{2} \frac{E}{E+\phi K_{2} H} \Delta e_{t}+\alpha_{2} \frac{\phi K_{2} H}{E+\phi K_{2} H}\left[\Delta k_{2 t}+\Delta h_{t}\right]
$$

In general, the bias depends critically on the correlation between the right hand side regressors. As a useful benchmark suppose that $\Delta k_{2 t}=\Delta k_{1 t}=0$, so that $\Delta e_{t}=\Delta h_{t}$. This is the case in which all variation in capital services corresponds to changes in the workweek of capital. Then (23) can be written as

$$
\Delta y_{t}=\Delta a_{t}+\alpha_{1} \Delta l_{t}+\alpha_{2} \Delta e_{t}
$$


so that there is no bias whatsoever. A similar argument would hold had we written the production function as $Y_{t}=A_{t}\left(L_{t}\right)^{\alpha_{1}}\left(K_{1 t} H_{t}\right)^{\alpha_{2}}\left(K_{2 t} H_{t}\right)^{\alpha_{3}}$. Again the sum of the coefficients on $\Delta l_{t}$ and $\Delta\left(h_{t} k_{1 t}\right)=\Delta e_{t}$ would be a biased estimate of total returns to scale. But to the extent that $K_{1 t}$ and $K_{2 t}$ do not vary over the cycle the bias induced by working with the simple Leontief production structure will be small.

\subsection{Multiple Shifts}

In our empirical work we ignored the fact that the capital stock can be utilized more intensely if plants use discrete multiple shifts. The available shift data is scarce but suggests an interesting puzzle. In U.S. manufacturing the shift premium paid to workers is small. Kostiuk (1990) estimates a premium for the second and third shift of only 5.3\%. Despite the small shift premium, most industries whose production process does not require continuous operation make modest use of the second shift and little use of the third. Bils (1992) argues that industries bunch their production in a small number of shifts because of increasing returns to scale. Shapiro (1993) argues that the marginal premium is much higher than the commonly reported average shift premium. He estimates the marginal premium to be $25 \%$.

To discuss how the presence of multiple shifts could affect our estimates, we extend our basic model to allow for two production shifts. Suppose that output is given by

$$
Y_{t}=A_{t} H N_{1 t}^{\alpha_{1}} K_{t}^{\alpha_{2}}+A_{t} H N_{2 t}^{\alpha_{1}} K_{t}^{\alpha_{2}} .
$$

Here $N_{i t}$ denotes the number of workers employed in shift $i$, for $i=1,2$. To simplify the analysis, we assume that the shift length, $H$, is the same for both shifts. Taking a log linear approximation to (24), we obtain the following expression for the growth rate of $Y_{t}$ :

$$
\Delta y_{t}=\Delta a_{t}+\alpha_{1}\left[\frac{N_{1}^{\alpha_{1}}}{N_{1}^{\alpha_{1}}+N_{2}^{\alpha_{2}}} \Delta n_{1 t}+\frac{N_{2}^{\alpha_{1}}}{N_{1}^{\alpha_{1}}+N_{2}^{\alpha_{2}}} \Delta n_{2 t}\right]+\alpha_{2} \Delta k_{t} .
$$

The specification used in our empirical work can be written as:

$$
\Delta y_{t}=\Delta a_{t}+\alpha_{1}\left[\frac{N_{1}}{N_{1}+N_{2}} \Delta n_{1 t}+\alpha_{1} \frac{N_{2}}{N_{1}+N_{2}} \Delta n_{2 t}\right]+\alpha_{2} \Delta k_{t} .
$$

Here $N_{1}$ and $N_{2}$ are the points about which we linearize the production function. To assess the specification error associated with neglecting multiple shifts, we can compare the coefficients used to aggregate $\Delta n_{1 t}$ and $\Delta n_{2 t}$ in (25) and (26). Shapiro (1993) reports that, for his 
sample of non-continuous processor industries, the percentage of workers on the first, second and third shifts is $68.2 \%, 20.7 \%$ and $11.1 \%$, respectively. Suppose we aggregate the second and third shifts and assume that $\alpha_{1}$ is equal to .65. Then the implied coefficients on $\Delta n_{1 t}$ and $\Delta n_{2 t}$ in (25) are .681 and .319. The corresponding coefficients in (26) are .621 and .379. We conclude that while there is some bias, it is not of first order magnitude. The basic fact driving this result is the puzzle pointed out by Shapiro (1993); Why isn't there more shift work?

\section{Conclusion}

This paper presented evidence that capital utilization rates are sharply procyclical. Our evidence relies on an electricity based measure of capital services. Standard measures of capital services seriously understate the procyclicality of actual capital services and lead to misleading inference regarding cyclical movements in labor productivity and the degree of returns to scale in the economy. Our results have three important implications for macroeconomists. First, models that depend on large, increasing returns to scale as a source of large propagation effects are inconsistent with the data. Granted, given the sampling uncertainty asscociated with our parameter estimates, it is possible to maintain that there are small increasing returns to scale. But viewed overall, there is virtually no evidence to suggest that there are important deviations from constant returns to scale in the manufacturing industry. Second, existing RBC models which depend on large, volatile aggregate technology shocks and which predict that the growth rate of output is highly correlated with aggregate technology shoks are empirically implausible. Third, our results strongly support models which emphasizing cyclical movements in capital utilization rates as an important determinant of movements in conventional measures of total factor and labor productivity. It seems very difficult to rationalize the properties of electrical use by manufacturing industries in a way that does not involve substantial cyclical movements in capital utilization. 


\section{References}

1. Ballard Charles, Fullerton Don, Shoven, John and John Whalley (1985), General Equilibrium Models for Tax Policy Evaluation, Chicago University Press.

2. Bartlesman, Eric J. (1993) 'Of Empty Boxes: Returns to Scale Revisited', manuscript, Board of Governors.

3. Bartlesman, Eric J., Ricardo J. Caballero and Richard K. Lyons (1994), 'Customer and Supplier - Driven Externalities', American Economic Review, Vol. 84, 1075 - 1084.

4. Basu, Susanto (1993), 'Procyclical Productivity: Overhead Inputs or Cyclical Utilization?', manuscript, University of Michigan.

5. Basu, Susanto and John Fernald (1994a), 'Are Apparent Productive Spillovers a Figment of Specification Error?', International Finance Discussion Paper 463, Federal Reserve Board.

6. Basu, Susanto and John Fernald (1994b), 'Constant Returns to Scale and Small Markups in U.S. Manufacturing', International Finance Discussion Paper 483, Federal Reserve Board.

7. Basu, Susanto and Kimball, Miles (1994), 'Cyclical Productivity with Unobserved Variation', manuscript, University of Michigan.

8. Bernanke, Ben and Martin Parkinson (1991), 'Procyclical Productivity and Competing Theories of the Business Cycle: Some Evidence from Interwar U.S. Manufacturing Industries', Journal of Political Economy, Vol. 99 (June), 439 - 459.

9. Berndt, Ernst and David Wood (1979), 'Engineering and Econometric Interpretations of Energy-Capital Complementarity,' American Economic Review, 69:3, June, 342-354.

10. Bils, Mark (1992), 'Measuring Returns to Scale From Shift Practices in Manufacturing', manuscript, University of Rochester. 
11. Bils, Mark and Jang-Ok Cho (1994), 'Cyclical Factor Utilization', Journal of Monetary Economics, 33, 319-354.

12. Board of Governors of the Federal Reserve System, (1986), Industrial Production.

13. Bruno, Michael (1978), 'Duality, Intermediate Inputs and Value - Added', in Production Economics: A Dual Approach to Theory and Applications (Vol. 2), eds., M. Fuss and D. McFadden, Amsterdam, North-Holland, pp.3-16.

14. Burnside, Craig (1994), 'What Do Production Regressions Tell Us About Increasing Returns to Scale and Externalities?', manuscript, University of Pittsburgh.

15. Burnside, Craig and Martin Eichenbaum (1994), 'Factor Hoarding and the Propagation of Business Cycles', NBER Working Paper 4675.

16. Burnside, Craig, Martin Eichenbaum and Sergio Rebelo (1993) 'Labor Hoarding and the Business Cycle', Journal of Political Economy, Vol. 101 (April), 245 - 273.

17. Caballero, Ricardo J., and Richard K. Lyons, (1992), 'External Effects and in U.S. Procyclical Productivity', Journal of Monetary Economics, 29, 209-226.

18. Chari, V.V., Lawrence Christiano and Martin Eichenbaum (1994), 'Inside Money, Interest Rates and the Business Cycle', forthcoming, Journal of Money, Credit and Banking.

19. Christiano, Lawrence J. (1988), 'Why Does Inventory Investment Fluctuate So Much?', Journal of Monetary Economics, Vol. 21, 247 - 280.

20. Christiano, Lawrence J. and Martin Eichenbaum (1992), 'Current Real Business Cycle Theories and Aggregate Labor Market Fluctuations', American Economic Review, Vol. $82,430-450$.

21. Christiano, Lawrence J., Martin Eichenbaum and Charles L. Evans (1994), 'The Effects of Monetary Policy Shocks: Some Evidence From The Flow of Funds', NBER Working Paper 4699, forthcoming, Review of Economics and Statistics. 
22. Costello, Donna (1993), 'A Cross-Country, Cross-Industry Comparison of Productivity Growth', Journal of Political Economy, Vol. 101 (April), 207 - 222.

23. Eichenbaum, Martin, Lars P. Hansen and Kenneth J. Singleton (1988), 'A Time Series Analysis of Representative Agent Models of Consumption and Leisure Under Uncertainty,' Quarterly Journal of Economics, Vol. CIII, 51-78.

24. Fabricant, Solomon (1942), Employment in Manufacturing, 1899 - 1939: An Analysis of Its Relation to the Volume of Production, NBER, New York.

25. Farmer, Roger and Jang - Ting Guo (1994), 'The Econometrics of Indeterminacy: an Applied Study', forthcoming, Carnegie-Rochester Conference on Public Policy.

26. Finn, Mary (1991) 'Energy, Price Shocks, Capacity Utilization and Business Cycle Fluctuations', Institute for Empirical Macroeconomics, Discussion Paper 50, Federal Reserve Bank of Minneapolis, Minneapolis, Minnesota.

27. Foss, Murray (1981), 'Long Run Changes in the Workweek of Fixed Capital', American Economic Review, Vol. 71, 58 - 63.

28. Greenwood, Jeremy, Zvi Hercowitz and Gregory W. Huffman (1988), 'Investment, Capacity Utilization and the Real Business Cycle', American Economic Review, Vol. $78,402-417$.

29. Griliches, Zvi and Dale Jorgenson (1967), 'The Explanation of Productivity Change', Review of Economic Studies, Vol. 34, 249-283.

30. Hall, George (1994), 'Overtime, Effort and the Propagation of Business Cycle Shocks', Federal Reserve Bank of Chicago Working Paper No. 94-25.

31. Hall, Robert E. (1988), 'The Relation Between Price and Marginal Cost in U.S. Industry', Journal of Political Economy, Vol. 96, 921-948.

32. Hall, Robert E. (1990), 'Invariance Properties and Solow's Productivity Residual', in Peter A. Diamond, ed. Growth/Productivity/Employment, Cambridge, MA: MIT, 71112. 
33. Hansen, Lars P. (1982), 'Large Sample Properties of Generalized Moments' Econometrica, Vol. 50, 1029-1054.

34. Jorgenson, Dale, Gollop, Frank and Barbara Fraumeni (1987), Productivity and US Economic Growth, Cambridge, Harvard University Press.

35. Kydland, Finn and Edward C. Prescott (1982), 'Time to Build and Aggregate Fluctuations', Econometrica, Vol. 50, 1345 - 1370.

36. Kydland, Finn and Edward C. Prescott (1988), 'The Workweek of Capital and its Cyclical Implications', Journal of Monetary Economics, Vol. 21, 343-360.

37. Kostiuk, Peter (1990), 'Compensating Differentials for Shift Work,' Journal of Political Economy, Vol. 98, 1055-75.

38. Long, John and Charles Plosser (1983), 'Real Business Cycles', Journal of Political Economy, Vol. 91, 39 - 69.

39. Lucas, Robert E. Jr. (1970), 'Capacity, Overtime, and Empirical Production Functions', American Economic Review: Papers and Proceedings, Vol. 60, 23-27.

40. Mankiw, N. Gregory and David Romer (1991), New Keynesian Economics, The MIT Press, Cambridge, Massachusetts.

41. Miron, Jeffrey A. and Steve Zeldes (1989), 'Production, Sales and the Change in Inventories: An Identity That Doesn't Add Up', Journal of Monetary Economics, Vol. $24,31-52$.

42. Perry, George L. (1973), 'Capacity in Manufacturing', Brookings Papers on Economic Activity, Vol. 3, $701-742$.

43. Ramey, Valery (1989), 'Inventories and Factors of Production and Economic Fluctuations', American Economic Review, Vol. 79, 338-354.

44. Rotemberg, Julio and Lawrence Summers (1990), 'Inflexible Prices and Procyclical Productivity', Quarterly Journal of Economics, Vol. 105, 851-874. 
45. Rotemberg, Julio and Michael Woodford (1995), Dynamic General Equilibrium Models with Imperfectly Competitive Product Markets', in Thomas F. Cooley (ed.) Frontiers in Business Cycle Research, Princeton University Press, Princeton, New Jersey.

46. Sato, Kazuo (1967), 'A Two Level CES Production Function', Review of Economic Studies, Vol. 34, 201 - 218.

47. Shapiro, Matthew (1993), 'Capital Utilization and the Premium for Working at Night', manuscript University of Michigan.

48. Shapiro, Matthew D. (1993a), 'Cyclical Productivity and the Workweek of Capital', American Economic Review: Papers and Proceedings, Vol. 83, 229-233.

49. Shea, John (1993a), 'The Input Selection Approach to Instrument Selection', Journal of Business and Economic Statistics, Vol. 11, 145- 155.

50. Shea, John (1993b), 'Do Supply Curves Slope Up?', Quarterly Journal of Economics, Vol. 108, 1 - 32.

51. Solow, Robert M. (1957), 'Technical Change and the Aggregate Production Function', Review of Economics and Statistics, Vol. 39, 312-320.

52. Solow Robert M. (1964), 'Draft of Presidential Address: On The Short-Run Relation of Employment and Output', manuscript, MIT. 


\section{APPENDIX A}

In this appendix, we summarize the 2 and 3 digit SIC codes of the manufacturing industries considered in the paper. In addition we summarize the sensitivity of the results we obtained with the 2 digit SIC industries to disregarding industries in which a particularly large percent of the Board's output measure is based on input data.

In our analysis we used the following 2 digit SIC industries.

\begin{tabular}{||l|l||}
\hline \hline \multicolumn{2}{||c||}{ 2 Digit SIC Industries } \\
\hline SIC Code & Name \\
20 & Food \\
21 & Textiles \\
23 & Apparel \\
24 & Wood Products \\
25 & Furniture \\
26 & Paper \\
27 & Printing - Publishing \\
28 & Chemicals \\
31 & Leather \\
32 & Stone, Clay and Glass \\
33 & Primary Metals \\
34 & Fabricated Metals \\
35 & Machinery \\
36 & Electrical Machinery \\
37 & Transportation Equipment \\
38 & Instruments \\
39 & Miscellaneous \\
\hline \hline
\end{tabular}

The following 3 digit SIC industries were used in our analysis. 


\begin{tabular}{||l|l|l||}
\hline \multicolumn{3}{|c||}{ 3 Digit SIC Industries } \\
\hline SIC Code & Name & Ouput Units \\
\hline 201 & Meat Products & Pounds \\
202 & Dairy Products & Pounds or Gallons \\
207 & Fats and Oils & Pounds \\
212 & Cigars & Units \\
221,2 & Cotton and Synthetic Fabrics & Bales or Linear Yards \\
226 & Fabric Finishing & Linear Yards \\
227 & Carpeting & Square Yards \\
228 & Yarns and Thread & Pounds \\
245 & Manufactured Homes & Units \\
262 & Paper & Tons \\
263 & Paper Board & Tons \\
265 & Paperboard Containers & Feet \\
271 & Newspapers & Tons \\
281 & Basic Chemicals & Tons or Cubic Feet \\
282 & Synthetic Materials & Pounds or Tons \\
285 & Paint & Gallons \\
301 & Tires & Units \\
314 & Shoes & Pairs \\
324 & Cement & Barrels \\
325 & Structural Clay Products & Units \\
331 & Basic Steel and Mill Products & Tons \\
332 & Iron and Steel Foundries & Tons \\
333 & Primary Nonferrous Metals & Tons \\
334 & Secondary Nonferrous Metals & Tons \\
336 & Nonferrous Foundries & Pounds \\
374 & Railroad Equipment & Units \\
\hline \hline
\end{tabular}

To assess the robustness of our results we redid the analysis underlying Table 4 excluding two subsets of industries. Excluding SIC Industries 23, 25, 34, 35, 38 and 39 leaves us with industries in which at least $30 \%$ of the Board's measure of output is based on physical output. If in addition we exclude SIC Industries $27,28,32$, and 36 , we are left with a panel of industries in which at least $40 \%$ of the Board's measure of output is based on physical output. All of the results in the following table refer to restricted panel estimates based on quarterly data.. 


\begin{tabular}{|c|c|c|c|c|c|c|c|c|c|}
\hline \multicolumn{10}{|c|}{ Table A.1, 2 Digit SIC Data } \\
\hline \multicolumn{10}{|c|}{$\Delta y_{t}=\gamma_{0}+\alpha_{1} \Delta l_{t}+\alpha_{2} \Delta e_{t}+\epsilon_{t}$} \\
\hline & \multirow{2}{*}{\multicolumn{3}{|c|}{ All 2 Digit SIC industries }} & \multirow{2}{*}{\multicolumn{3}{|c|}{$\begin{array}{c}\text { Exclude SIC } 23,25 \\
34,35,38,39\end{array}$}} & \multirow{2}{*}{\multicolumn{3}{|c|}{ Also Exclude SIC 27, 28, }} \\
\hline & & & & & & & & & \\
\hline & Manuf. & Dur. & Nondur. & Manuf. & Dur. & Nondur. & Manuf. & Dur. & Nondur. \\
\hline$\alpha_{1}$ & $\begin{array}{l}.64 \\
.05)\end{array}$ & $\begin{array}{c}(.61 \\
(.06)\end{array}$ & $\begin{array}{l}7.74 \\
(.09)\end{array}$ & $\begin{array}{l}75 \\
(.06)\end{array}$ & $\begin{array}{c}8.84 \\
(.10)\end{array}$ & $\begin{array}{l}0.67 \\
(.10)\end{array}$ & $\begin{array}{l}.82 \\
.09)\end{array}$ & $\begin{array}{c}9.98 \\
(.14)\end{array}$ & .61 \\
\hline$\alpha_{2}$ & 37 & 43 & 39 & 32 & 24 & 47 & 27 & .13 & 51 \\
\hline$J_{1}$ & .31 & .12 & .30 & .20 & .07 & .42 & .46 & .16 & .51 \\
\hline$J_{2}$ & .75 & .38 & .10 & .18 & .15 & .09 & .09 & .10 & .22 \\
\hline$\sigma_{\epsilon} / \sigma_{\Delta Y}$ & .59 & .57 & .63 & .60 & .52 & .69 & .59 & .50 & .63 \\
\hline$\rho_{\epsilon \Delta Y}$ & .66 & .59 & .60 & .56 & .42 & .55 & .53 & .45 & .55 \\
\hline
\end{tabular}



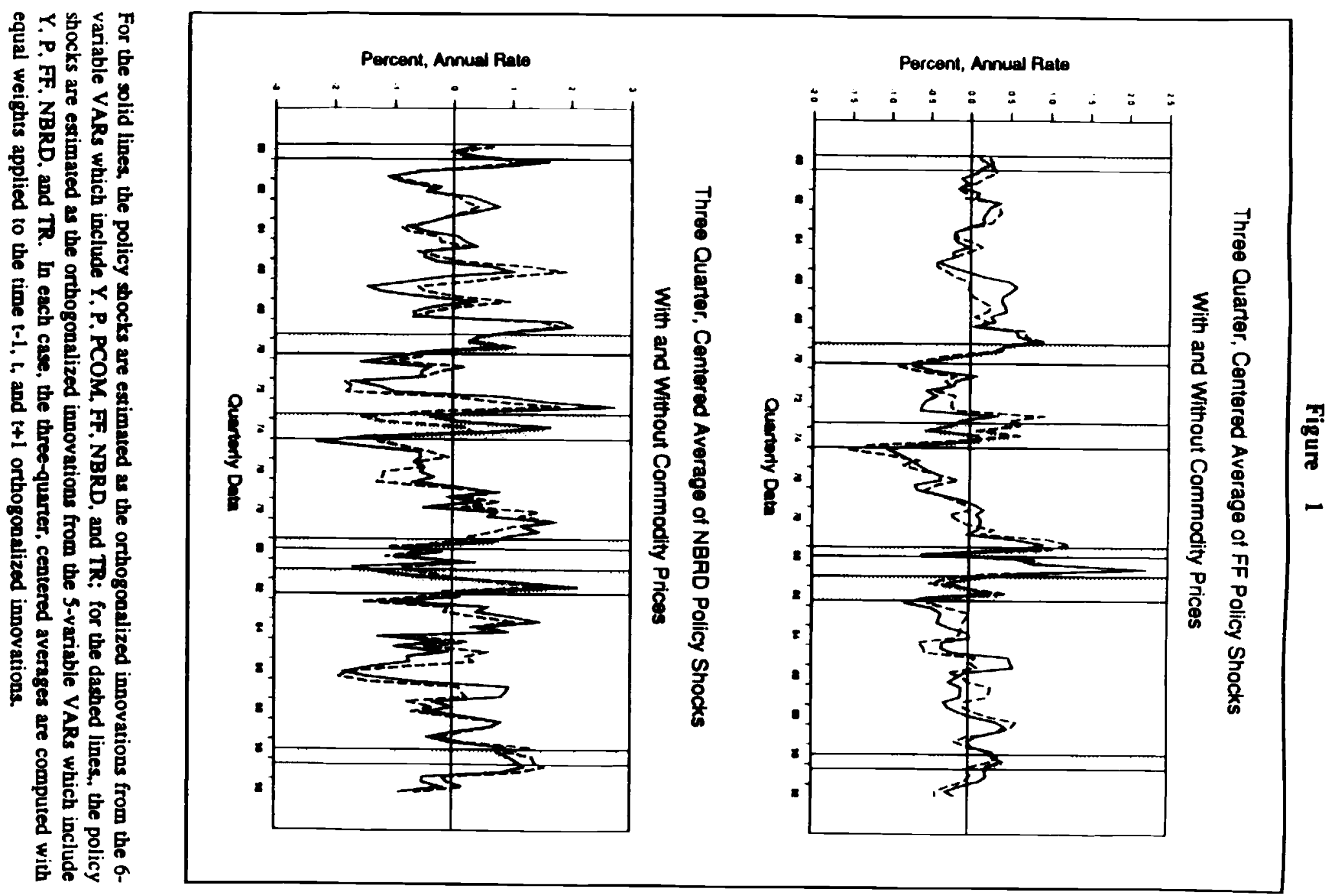


\section{Figure 2}

\section{Quarterly Growth Rates of Economy Wide Data*}

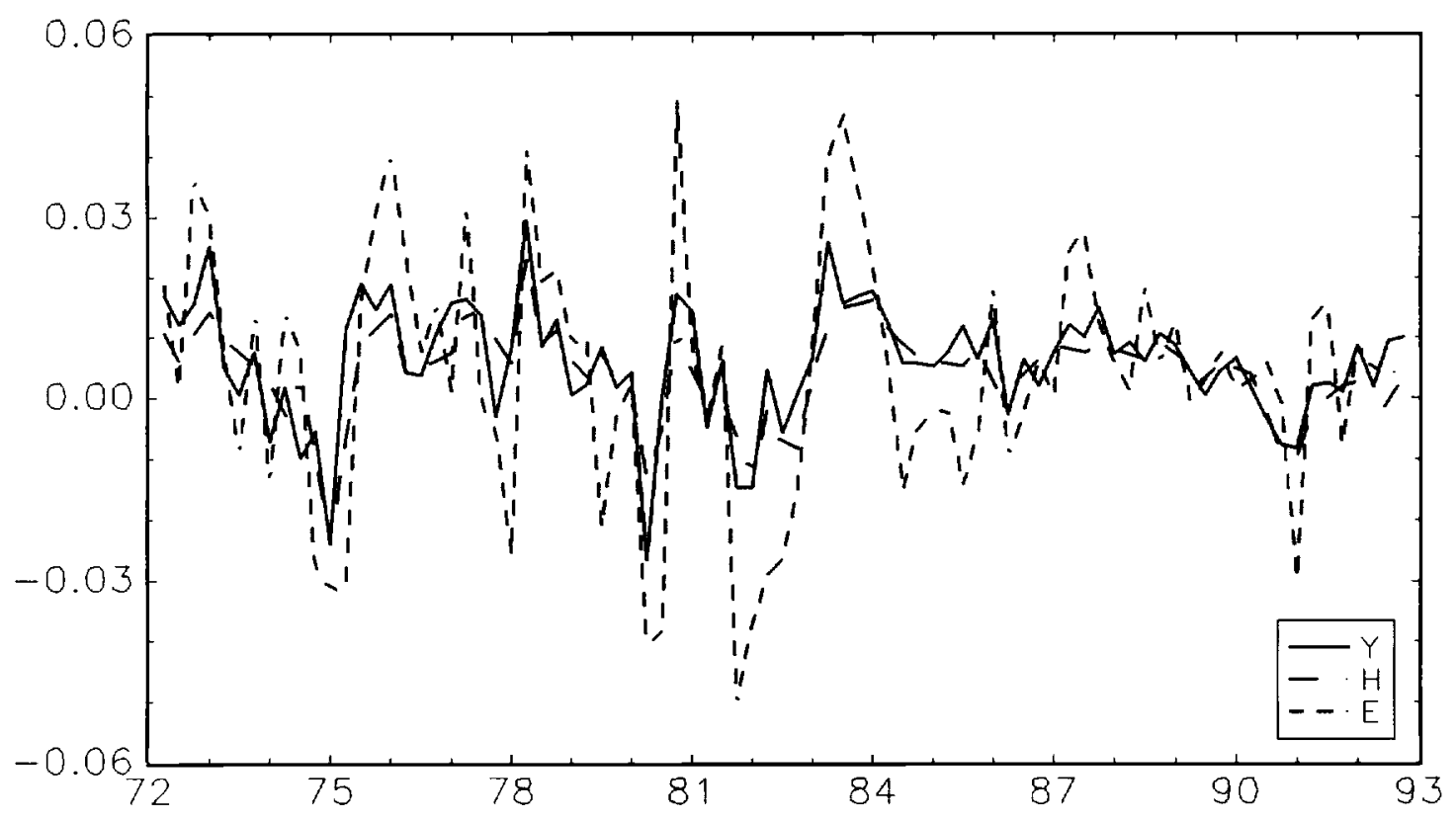

* $Y$ represents real GNP, $H$ represents total hours worked in nonagricultural establishments and $E$ represents electrical power usage in the industrial sector. All series are plotted as first-differenced logarithms. The data are described in more detail in the text. 
Figure 3

Quarterly Growth Rates of Aggregate Manufacturing Data*

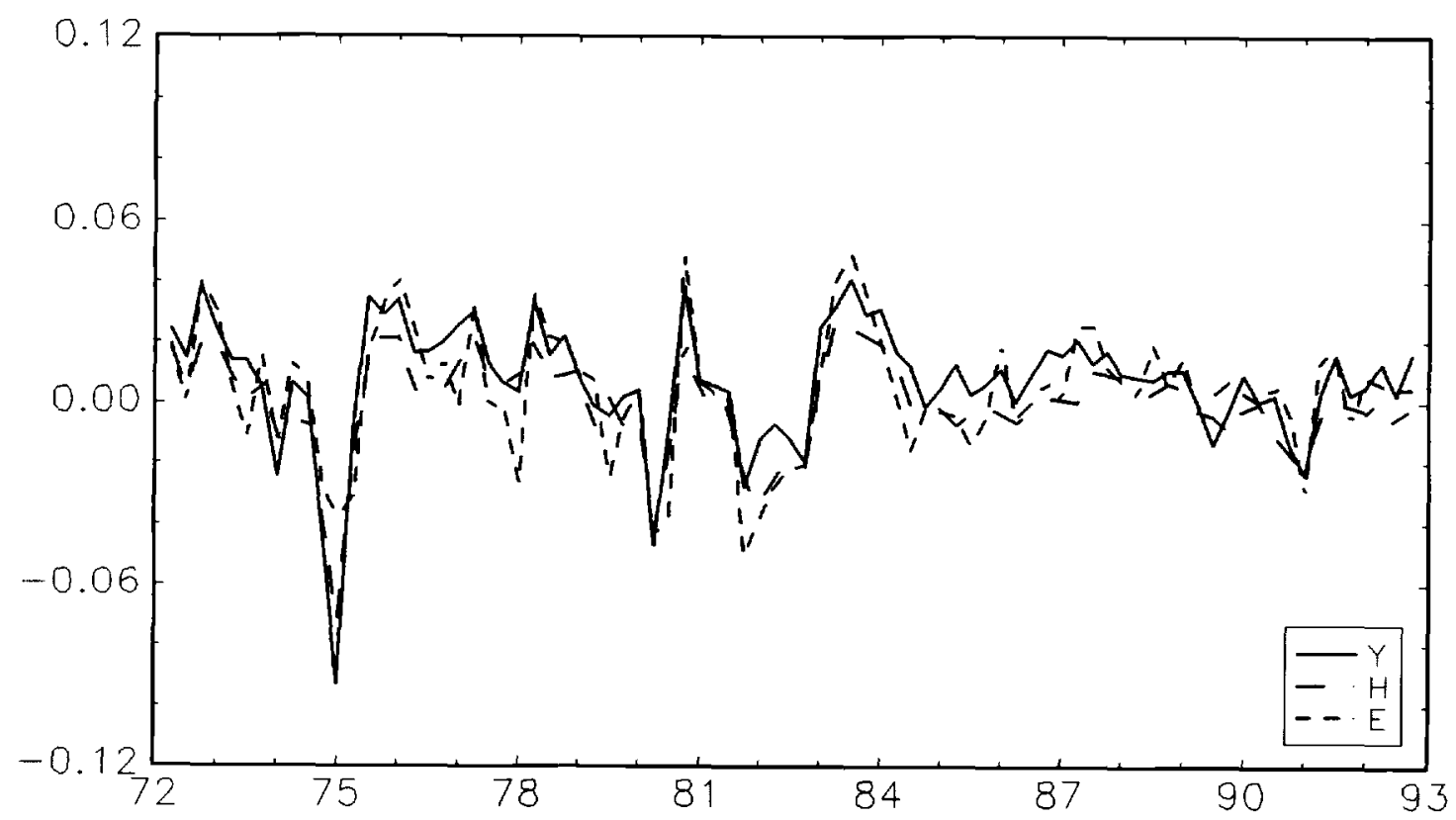

* $Y$ represents industrial production in the manufacturing sector, $H$ represents total employee hours in the manufacturing sector, and $E$ represents electrical power usage in the manufacturing sector. All series are plotted as first-differenced logarithms. The data are described in more detail in the text. 
Figure 4

Annual Growth Rates of Aggregate Manufacturing Data*

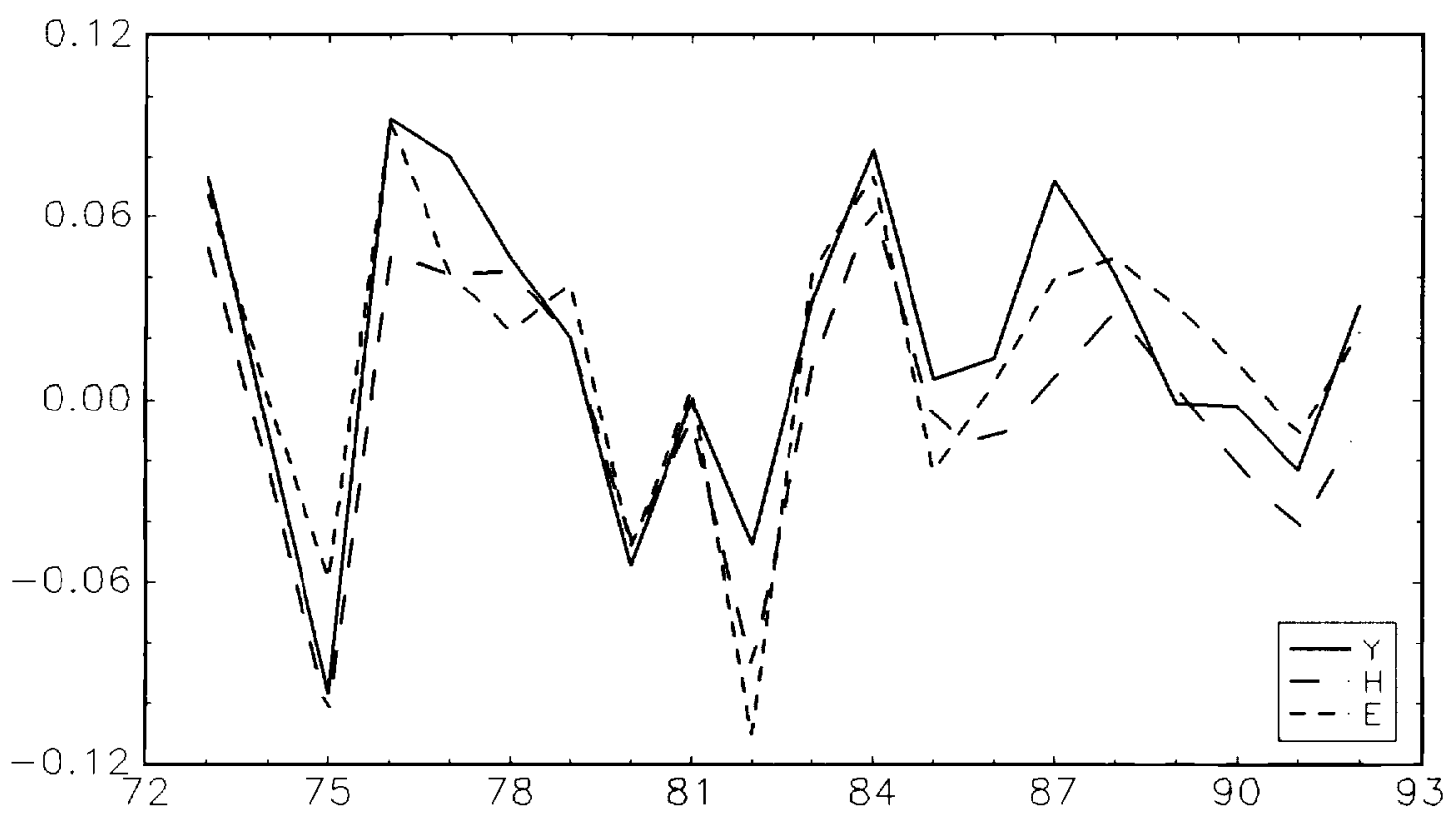

* $Y$ represents gross output in the manufacturing sector, $H$ represents total employee hours in the manufacturing sector, and $E$ represents electrical power usage in the manufacturing sector. All series are plotted as first-differenced logarithms. The data are described in more detail in the text. 
Figure 5

Correlations of Quarterly 2-Digit SiC level Data*

Output and Hours
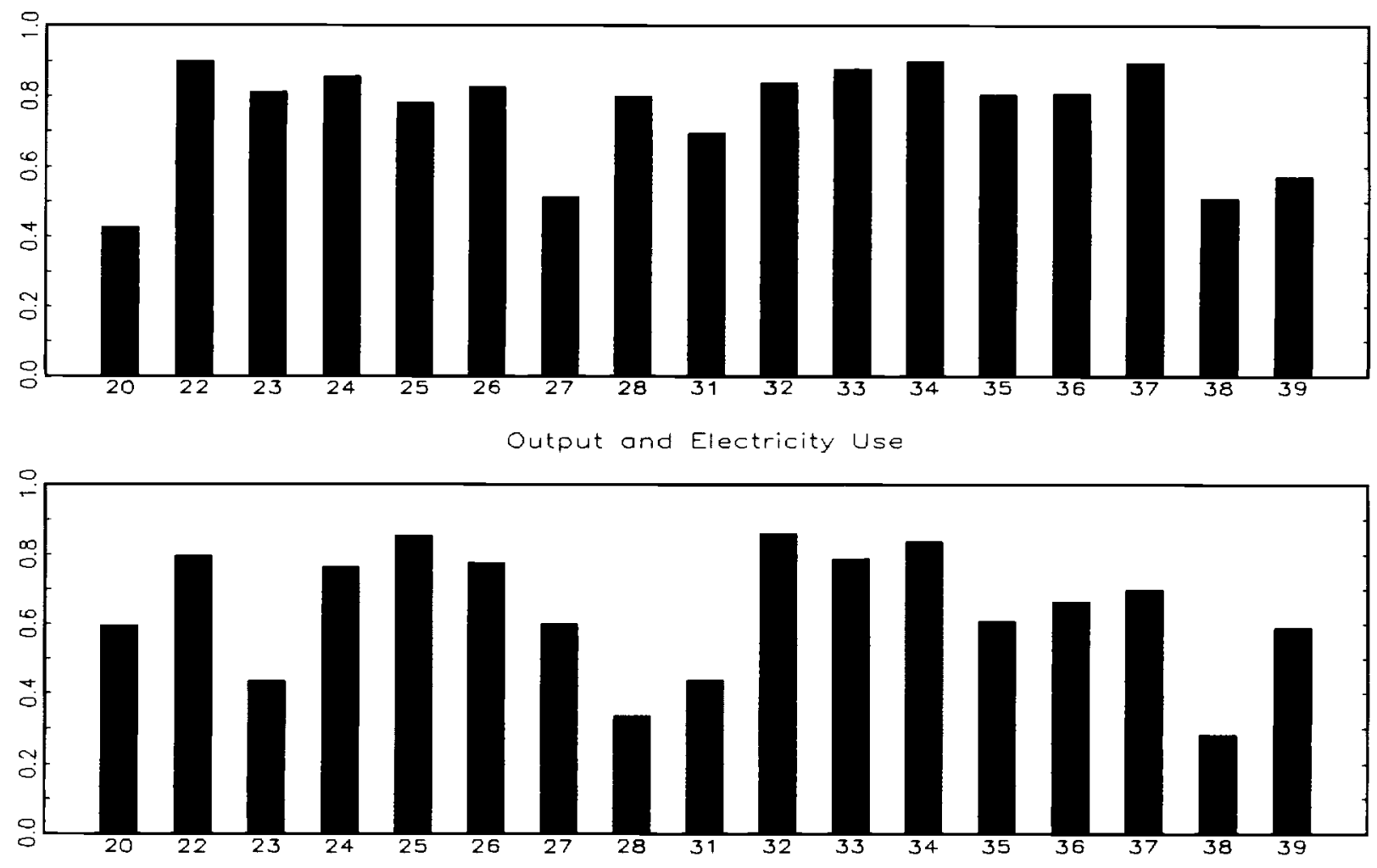

Hours and Electricity Use

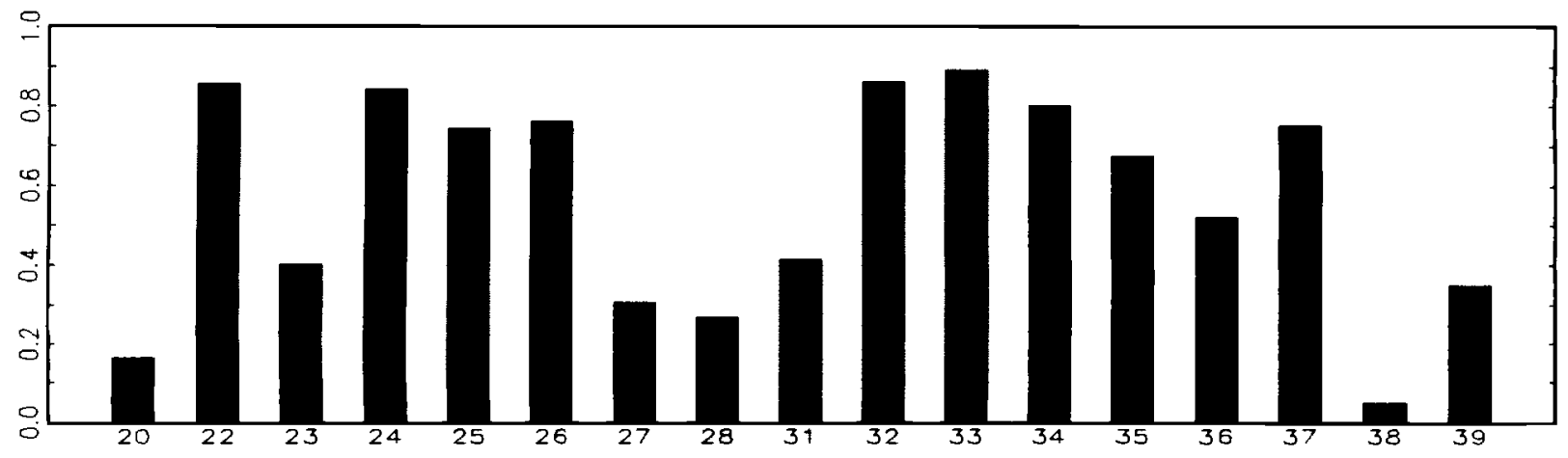

* $Y$ represents industrial production, $H$ represents production worker hours and $E$ represents electrical power usage. All series are first-differenced logarithms. The $x$-axis labels are the appropriate SIC codes. 
Figure 6

Correlations of Annual 2-Digit SiC Level Data*

Output and Hours

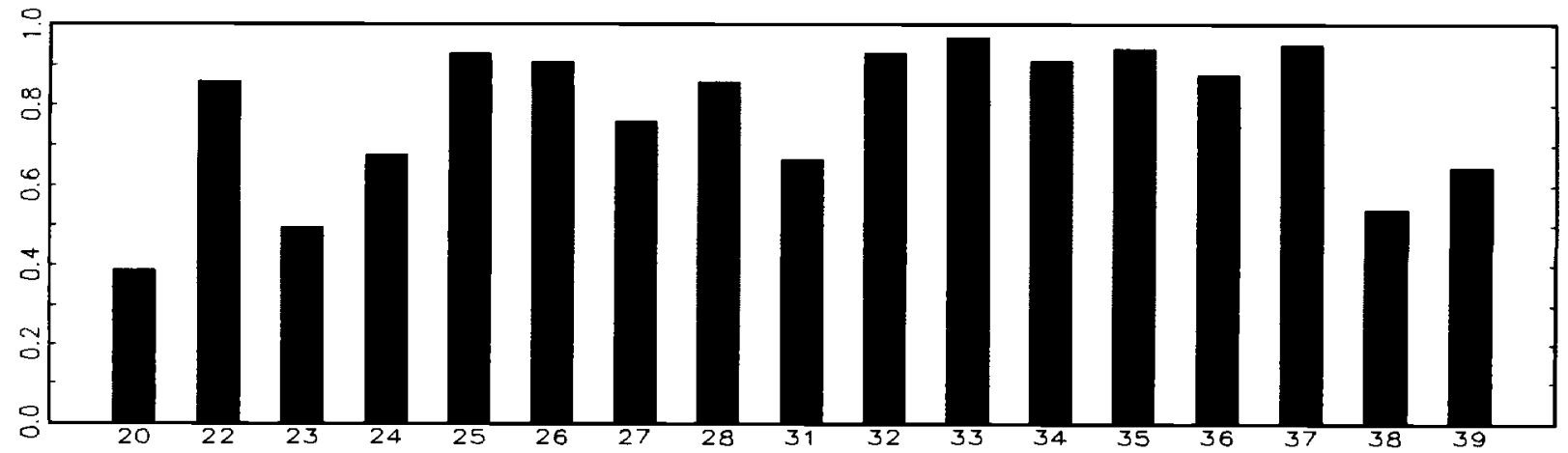

Output and Electricity Use

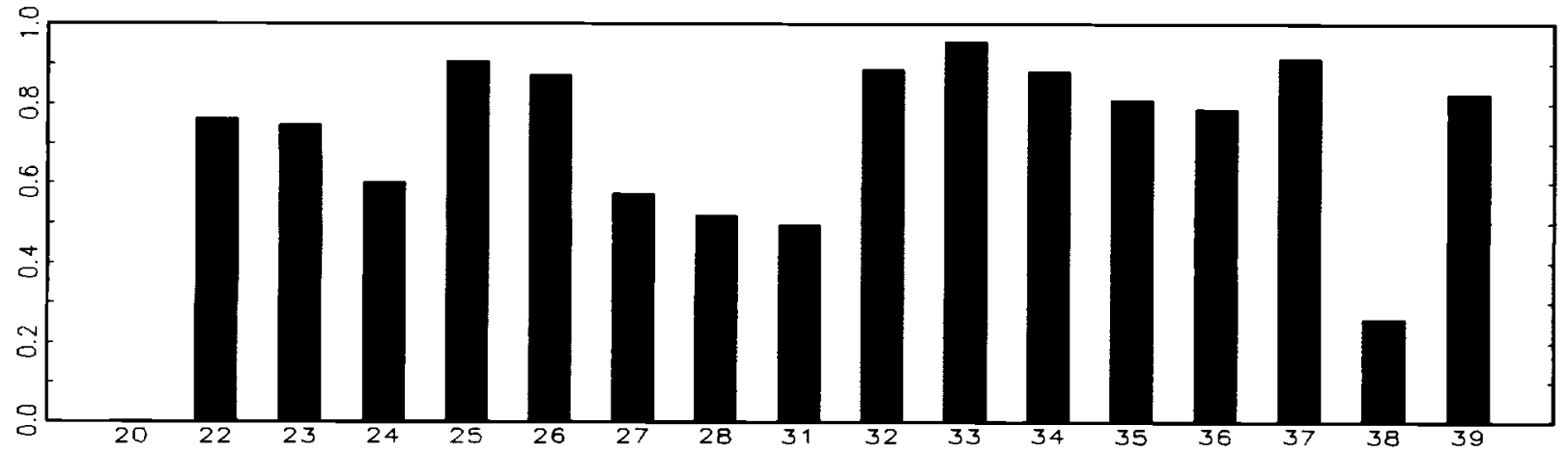

Hours and Electricity Use

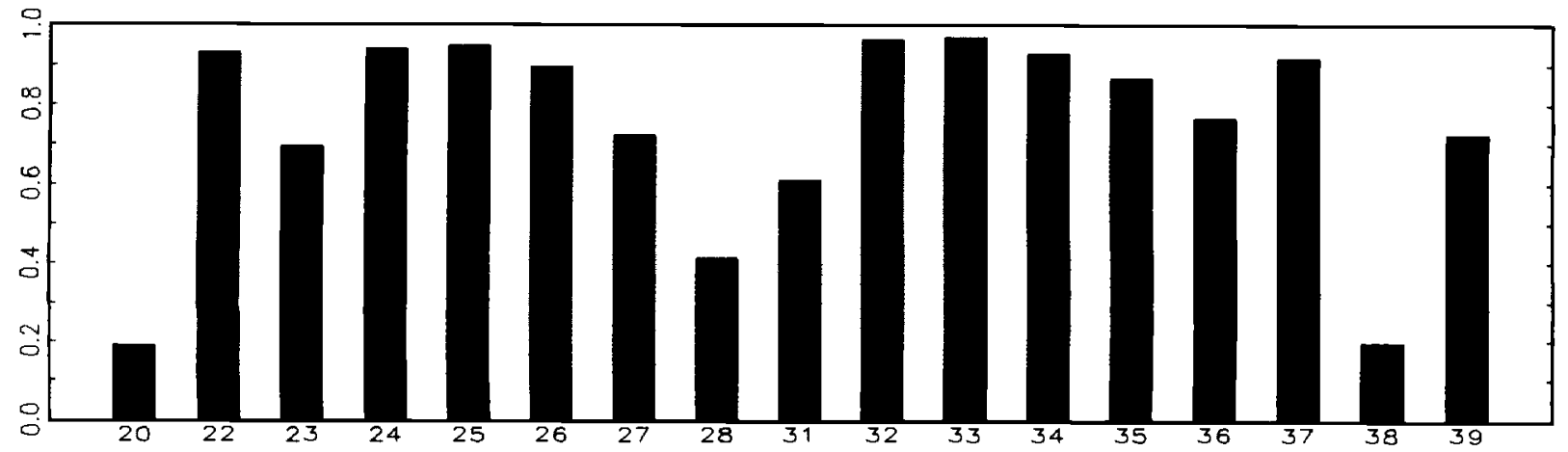

${ }^{*} Y$ represents industrial production, $H$ represents production worker hours and $E$ represents electrical power usage. All series are first-differenced logarithms. The $x$-axis labels are the appropriate SIC codes. The correlation between $Y$ and $E$ for industry 20 is -0.19 . 


\section{Figure 7}

\section{Correlations of Quarterly 3-Digit SIC Level Data*}

Output and Hours

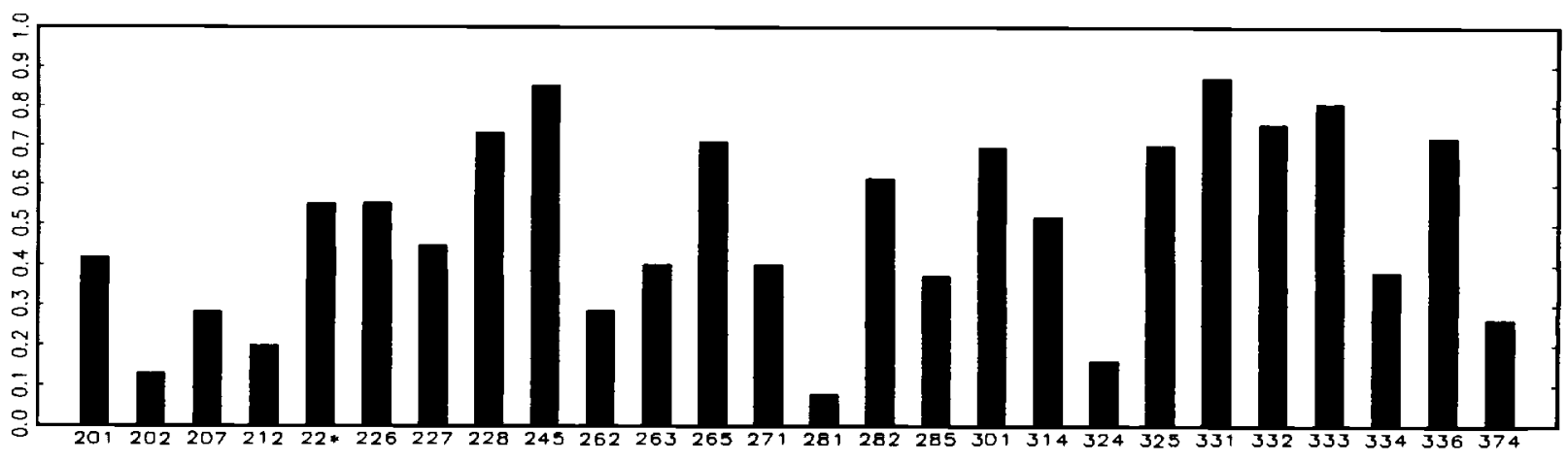

Output and Electricity Use

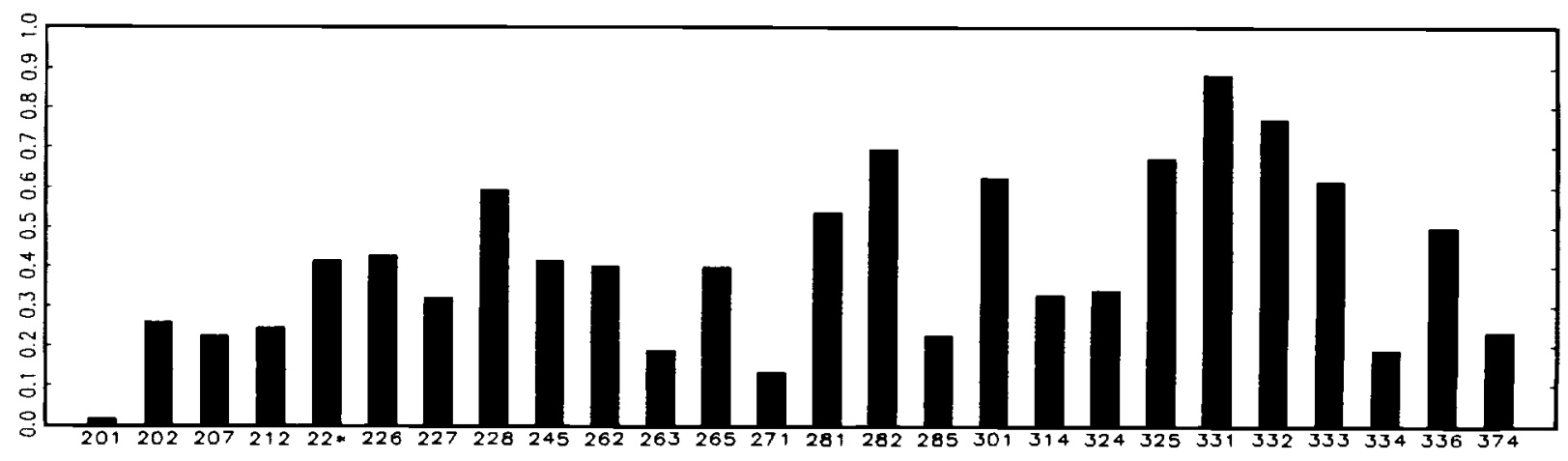

Hours and Electricity Use

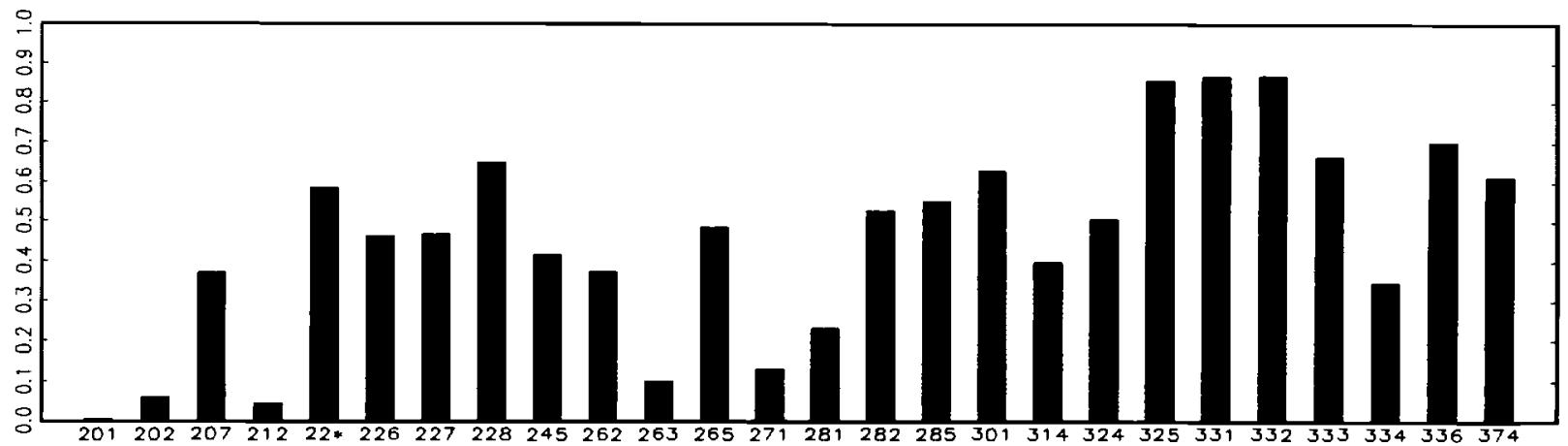

* $Y$ represents industrial production, $H$ represents production worker hours and $E$ represents electrical power usage. All series are first-differenced logarithms. The $x$-axis labels are the appropriate SIC codes. Industry $22^{*}$ is industries 221 and 222 combined. The correlation between $H$ and $E$ for industry 201 is -0.03 . 


\begin{tabular}{||l|c|c|c||}
\hline \hline \multicolumn{3}{|c||}{ Table 1: $R^{2}$ of Instrument Lists with Output and Inputs } \\
\hline \hline \multirow{3}{*}{ Sector } & \multicolumn{3}{|c||}{ Hall Instruments* } \\
\cline { 2 - 4 } & Output & Hours & Electricity \\
\hline Manufacturing & 0.10 & 0.09 & 0.05 \\
Durables & 0.10 & 0.09 & 0.03 \\
Nondurables & 0.09 & 0.09 & 0.08 \\
\hline \multirow{4}{*}{ Sector } & \multicolumn{2}{|c||}{ Growth Rate of Oil Price: Lags 0-3 } \\
\cline { 2 - 4 } Manufacturing & Output & Hours & Electricity \\
Durables & 0.07 & 0.06 & 0.02 \\
Nondurables & 0.07 & 0.05 & 0.00 \\
\hline \multirow{4}{*}{ Sector } & 0.07 & 0.08 & 0.03 \\
\hline Manufacturing & \multicolumn{3}{|c||}{ Benchmark Instruments } \\
\cline { 2 - 4 } Durables & 0.42 & Hours & Electricity \\
Nondurables & 0.40 & 0.38 & 0.34 \\
\hline * Growth Rate of Oil Price, Lags 0-3; Growth Rate of Military Spending, Lags 0-3 \\
† Growth Rate of Oil Price, Lags 1-4; $\epsilon_{F F t}$ Shock, Lags 3-6; $\epsilon_{N B R t}$ Shock, Lags 3-6 \\
\hline \hline
\end{tabular}

\begin{tabular}{||l|c|c|c|c|c||}
\hline \hline \multicolumn{5}{|c||}{ Table 2: CES Specifications } \\
\hline \hline \multirow{4}{*}{$\alpha_{1}$} & Economy Wide & \multicolumn{4}{|c||}{ Manufacturing Sector } \\
\cline { 2 - 6 } & & Aggregate & \multicolumn{2}{|c||}{ 2 Digit SIC Code Level } \\
\cline { 2 - 6 } & & & All Industries & Durables & Nondurables $^{*}$ \\
\cline { 2 - 6 }$\alpha_{2}$ & 0.74 & 0.71 & 0.76 & 0.63 & 0.90 \\
& $(0.50)$ & $(0.34)$ & $(0.09)$ & $(0.13)$ & $(0.15)$ \\
& 0.24 & 0.30 & 0.27 & 0.41 & 0.27 \\
$\sigma$ & $(0.17)$ & $(0.30)$ & $(0.08)$ & $(0.12)$ & $(0.12)$ \\
& 0.15 & 0.03 & 0.26 & 0.04 & 0.30 \\
& $(0.35)$ & $(0.44)$ & $(0.17)$ & $(0.20)$ & $(0.22)$ \\
\hline \multirow{2}{*}{$\alpha_{1}+\alpha_{2}$} & 0.98 & 1.00 & 1.03 & 1.04 & 1.17 \\
& $(0.34)$ & $(0.08)$ & $(0.04)$ & $(0.05)$ & $(0.08)$ \\
\hline$J$ & 0.92 & 0.004 & 0.34 & 0.11 & 0.33 \\
\hline$\sigma_{\epsilon} / \sigma_{\Delta Y}$ & 0.60 & 0.37 & 0.63 & 0.60 & 0.67 \\
$\rho_{\epsilon, \Delta Y}$ & 0.32 & 0.21 & 0.54 & 0.42 & 0.56 \\
\hline$*$ Coefficients restricted across industries, with industry fixed effects \\
\hline \hline
\end{tabular}




\begin{tabular}{||l|c|c|c||}
\hline \hline \multicolumn{4}{|c||}{ Table 3: Economy Wide Data } \\
\hline \hline \multicolumn{3}{|c||}{$\Delta Y_{t}=\alpha_{0}+\alpha_{1} \Delta H_{t}+\alpha_{2} \Delta K_{t}^{*}+\epsilon_{t}$} \\
\hline \hline \multirow{3}{*}{$\alpha_{1}$} & $\Delta K^{*}=\Delta K^{H}$ & $\Delta K^{*}=\Delta K^{C}$ & $\Delta K^{*}=\Delta E$ \\
\cline { 2 - 4 } & 1.23 & 1.31 & 0.54 \\
$\alpha_{2}$ & $(0.14)$ & $(0.24)$ & $(0.27)$ \\
& -0.32 & -0.88 & 0.30 \\
& $(0.85)$ & $(1.81)$ & $(0.11)$ \\
\hline \multirow{2}{*}{$\alpha_{1}+\alpha_{2}$} & 0.91 & 0.43 & 0.84 \\
& $(0.80)$ & $(1.61)$ & $(0.19)$ \\
\hline$J$ & 0.91 & 0.72 & 0.41 \\
\hline$\sigma_{\varepsilon} / \sigma_{\Delta Y}$ & 0.56 & 0.56 & 0.60 \\
$\rho_{\epsilon, \Delta Y}$ & 0.38 & 0.39 & 0.31 \\
\hline$K^{H}:$ Hall (1994) measure of capital \\
$K^{C}:$ Christiano (1988) measure of capital: $72: 1-88: 4$ \\
\hline \hline
\end{tabular}

\begin{tabular}{|c|c|c|c|c|c|c|c|c|}
\hline \multicolumn{9}{|c|}{ Table 4: Manufacturing Sector Data } \\
\hline \multicolumn{9}{|c|}{$\Delta Y_{t}=\alpha_{0}+\alpha_{1} \Delta H_{t}+\alpha_{2} \Delta K_{t}^{*}+\epsilon_{t}$} \\
\hline \multirow[b]{4}{*}{$\alpha_{1}$} & & \multicolumn{4}{|c|}{ Annual } \\
\hline & \multicolumn{2}{|c|}{ Manufacturing } & \multicolumn{2}{|l|}{ Durables } & \multicolumn{2}{|c|}{ Manufacturing } & Durables & Nondur. \\
\hline & Aggregate & \multicolumn{3}{|c|}{ 2-Digit SIC Code Level ${ }^{*}$} & Aggregate & \multicolumn{3}{|c|}{ 2-Digit SIC Code Level ${ }^{*}$} \\
\hline & $\begin{array}{l}0.69 \\
(0.16)\end{array}$ & $\begin{array}{l}0.64 \\
(0.05)\end{array}$ & $\begin{array}{l}0.61 \\
(0.06)\end{array}$ & $\begin{array}{l}0.74 \\
(0.09)\end{array}$ & $\begin{array}{l}0.69 \\
(0.31)\end{array}$ & $\begin{array}{l}0.43 \\
(0.02)\end{array}$ & $\begin{array}{l}0.38 \\
(0.06)\end{array}$ & $\begin{array}{l}0.60 \\
(0.12)\end{array}$ \\
\hline$\alpha_{2}$ & $\begin{array}{l}0.31 \\
(0.17)\end{array}$ & $\begin{array}{l}0.37 \\
(0.05)\end{array}$ & $\begin{array}{l}0.43 \\
(0.07)\end{array}$ & $\begin{array}{l}0.39 \\
(0.08)\end{array}$ & $\begin{array}{l}0.21 \\
(0.35)\end{array}$ & $\begin{array}{l}0.57 \\
(0.02)\end{array}$ & $\begin{array}{l}0.71 \\
(0.06)\end{array}$ & $\begin{array}{l}0.30 \\
(0.12)\end{array}$ \\
\hline$\alpha_{1}+\alpha_{2}$ & $\begin{array}{l}1.00 \\
(0.07)\end{array}$ & $\begin{array}{l}1.01 \\
(0.04)\end{array}$ & $\begin{array}{l}1.04 \\
(0.05)\end{array}$ & $\begin{array}{l}1.13 \\
(0.08)\end{array}$ & $\begin{array}{l}0.90 \\
(0.09)\end{array}$ & $\begin{array}{l}1.00 \\
(0.01)\end{array}$ & $\begin{array}{l}1.06 \\
(0.03)\end{array}$ & $\begin{array}{l}0.90 \\
(0.07)\end{array}$ \\
\hline$J$ & 0.01 & 0.31 & 0.12 & 0.30 & 0.12 & 0.20 & 0.44 & 0.09 \\
\hline$\sigma_{\epsilon} / \sigma_{\Delta Y}$ & 0.37 & 0.63 & 0.60 & 0.67 & 0.33 & 0.61 & 0.55 & 0.69 \\
\hline$\rho_{\varepsilon, \Delta Y}$ & 0.21 & 0.54 & 0.42 & 0.56 & 0.35 & 0.58 & 0.49 & 0.71 \\
\hline
\end{tabular}




\begin{tabular}{|c|c|c|c|c|c|c|}
\hline \multicolumn{7}{|c|}{ Table 5: 3-Digit SIC Code Level Data } \\
\hline \multicolumn{7}{|c|}{$\overline{\Delta Y_{t}=\alpha_{0}+\alpha_{1} \Delta H_{t}+\alpha_{2} \Delta K_{t}^{*}+\epsilon_{t}}$} \\
\hline & \multicolumn{3}{|c|}{ Restricted* ${ }^{*}$} & \multicolumn{3}{|c|}{ Unrestricted $^{\dagger}$} \\
\hline & Manufct'rng & Durables & Nondur. & Manufct'rng & Durables & Nondur. \\
\hline$\alpha_{1}$ & $\begin{array}{l}0.52 \\
(0.05)\end{array}$ & $\begin{array}{l}0.73 \\
(0.11)\end{array}$ & $\begin{array}{l}0.45 \\
(0.07)\end{array}$ & $\begin{array}{l}0.52 \\
(0.31)\end{array}$ & $\begin{array}{l}0.64 \\
(0.44)\end{array}$ & $\begin{array}{l}0.56 \\
(0.33)\end{array}$ \\
\hline$\alpha_{2}$ & $\begin{array}{l}0.35 \\
(0.04)\end{array}$ & $\begin{array}{l}0.14 \\
(0.08)\end{array}$ & $\begin{array}{l}0.35 \\
(0.06)\end{array}$ & $\begin{array}{l}0.38 \\
(0.25)\end{array}$ & $\begin{array}{l}0.24 \\
(0.36)\end{array}$ & $\begin{array}{l}0.21 \\
(0.26)\end{array}$ \\
\hline$\alpha_{1}+\alpha_{2}$ & $\begin{array}{l}0.86 \\
(0.05)\end{array}$ & $\begin{array}{l}0.87 \\
(0.08)\end{array}$ & $\begin{array}{l}0.81 \\
(0.09)\end{array}$ & $\begin{array}{l}0.87 \\
(0.28)\end{array}$ & $\begin{array}{c}0.89 \\
(0.23)\end{array}$ & $\begin{array}{l}0.92 \\
(0.32)\end{array}$ \\
\hline$J$ & 0.20 & 0.19 & 0.26 & 0.50 & 0.15 & 0.79 \\
\hline$\sigma_{\epsilon} / \sigma_{\Delta Y}$ & 0.84 & 0.75 & 0.88 & 0.95 & 0.70 & 0.97 \\
\hline$\rho_{\epsilon, \Delta Y}$ & 0.84 & 0.82 & 0.86 & 0.78 & 0.78 & 0.76 \\
\hline \multicolumn{7}{|c|}{$\begin{array}{l}\text { Coefficients restricted across industries, with industry fixed effects } \\
\dagger \text { Median coefficients across industries, with median standard errors reported } \\
\text { in parentheses }\end{array}$} \\
\hline
\end{tabular}

\begin{tabular}{|c|c|c|c|c|}
\hline \multicolumn{5}{|c|}{ Table 6: Hall Instruments } \\
\hline \multicolumn{5}{|c|}{$\overline{\Delta \Delta Y_{t}=\alpha_{0}+\alpha_{1} \Delta H_{t}+\alpha_{2} \Delta K_{t}^{*}+\epsilon_{t}}$} \\
\hline & \multicolumn{2}{|c|}{ 2-Digit SIC Code } & \multicolumn{2}{|c|}{ 3-Digit SIC Code } \\
\hline & Restricted $^{*}$ & Unrestricted $^{\dagger}$ & Restricted* & Unrestricted $^{\dagger}$ \\
\hline$\alpha_{1}$ & $\begin{array}{l}0.54 \\
(0.04)\end{array}$ & $\begin{array}{l}0.61 \\
(0.19)\end{array}$ & $\begin{array}{l}0.79 \\
(0.05)\end{array}$ & $\begin{array}{l}0.50 \\
(0.32)\end{array}$ \\
\hline$\alpha_{2}$ & $\begin{array}{l}0.39 \\
(0.04)\end{array}$ & $\begin{array}{l}0.29 \\
(0.18)\end{array}$ & $\begin{array}{l}0.23 \\
(0.04)\end{array}$ & $\begin{array}{l}0.20 \\
(0.25)\end{array}$ \\
\hline$\alpha_{1}+\alpha_{2}$ & $\begin{array}{l}0.93 \\
(0.04)\end{array}$ & $\begin{array}{l}0.91 \\
(0.20)\end{array}$ & $\begin{array}{l}0.79 \\
(0.05)\end{array}$ & $\begin{array}{l}0.79 \\
(0.28)\end{array}$ \\
\hline$J$ & 0.41 & 0.65 & 0.20 & 0.81 \\
\hline$\sigma_{\epsilon} / \sigma_{\Delta Y}$ & 0.62 & 0.58 & 0.83 & 0.91 \\
\hline$\rho_{\varepsilon, \Delta Y}$ & 0.63 & 0.61 & 0.87 & 0.85 \\
\hline
\end{tabular}




\begin{tabular}{|c|c|c|c|}
\hline \multicolumn{4}{|c|}{\begin{tabular}{l|c} 
Table 7: Differentiable Technology Specification \\
\end{tabular}} \\
\hline & $\Delta K_{t}$ & $\Delta e_{t}$ & $\Delta\left[w k_{t} \cdot K_{t}\right]$ \\
\hline \multicolumn{4}{|c|}{ Aggregate Manufacturing } \\
\hline$\eta$ & $\begin{array}{l}\mathbf{1 . 1 0} \\
(.06)\end{array}$ & $\begin{array}{c}\mathbf{1 . 0 1} \\
(.07)\end{array}$ & $\begin{array}{l}.98 \\
(.05)\end{array}$ \\
\hline$J_{1}$ & .05 & .07 & .27 \\
\hline$\sigma_{\epsilon} / \sigma_{\Delta y}$ & .24 & .24 & .17 \\
\hline$\rho_{\epsilon \Delta y}$ & .17 & .26 & 17 \\
\hline \multicolumn{4}{|c|}{ AggregateDurables } \\
\hline$\eta$ & $\begin{array}{c}\mathbf{1 . 1 6} \\
(.05)\end{array}$ & $\begin{array}{c}\mathbf{1 . 0 6} \\
(.05)\end{array}$ & $\begin{array}{l}1.08 \\
(.05)\end{array}$ \\
\hline$J_{1}$ & .35 & .20 & .30 \\
\hline$\sigma_{\epsilon} / \sigma_{\Delta y}$ & .18 & 16 & 17 \\
\hline$\rho_{\epsilon \Delta y}$ & -.08 & .11 & .14 \\
\hline \multicolumn{4}{|c|}{ Aggregate Non Durables } \\
\hline$\eta$ & $\begin{array}{c}83 \\
(.13)\end{array}$ & .82 & $\begin{array}{r}86 \\
(.12)\end{array}$ \\
\hline$J_{1}$ & .11 & .13 & .22 \\
\hline$\sigma_{\epsilon} / \sigma_{\Delta y}$ & .50 & .52 & 42 \\
\hline$\rho_{\epsilon \Delta y}$ & .67 & .61 & .43 \\
\hline
\end{tabular}

